IZA DP No. 10034

Trade Competition, Technology and Labour Reallocation

Selva Bahar Baziki

Rita Ginja

Teodora Borota Milicevic

July 2016 


\title{
Trade Competition, Technology and Labour Reallocation
}

\author{
Selva Bahar Baziki \\ Central Bank of the Republic of Turkey \\ Rita Ginja \\ Uppsala University, UCLS and IZA
}

Teodora Borota Milicevic

Uppsala University
Discussion Paper No. 10034
July 2016

IZA

P.O. Box 7240

53072 Bonn

Germany

Phone: +49-228-3894-0

Fax: +49-228-3894-180

E-mail: iza@iza.org

\begin{abstract}
Any opinions expressed here are those of the author(s) and not those of IZA. Research published in this series may include views on policy, but the institute itself takes no institutional policy positions. The IZA research network is committed to the IZA Guiding Principles of Research Integrity.

The Institute for the Study of Labor (IZA) in Bonn is a local and virtual international research center and a place of communication between science, politics and business. IZA is an independent nonprofit organization supported by Deutsche Post Foundation. The center is associated with the University of Bonn and offers a stimulating research environment through its international network, workshops and conferences, data service, project support, research visits and doctoral program. IZA engages in (i) original and internationally competitive research in all fields of labor economics, (ii) development of policy concepts, and (iii) dissemination of research results and concepts to the interested public.
\end{abstract}

IZA Discussion Papers often represent preliminary work and are circulated to encourage discussion. Citation of such a paper should account for its provisional character. A revised version may be available directly from the author. 


\section{ABSTRACT}

\section{Trade Competition, Technology and Labour Reallocation*}

This paper provides new evidence on the reallocation of workers across firms and industries with different technologies in response to increased import competition from developing countries. Using employer-employee matched data for the Swedish manufacturing sector, we find increased assortative matching of workers in ICT (information and communication technologies) intensive industries, that is, high(low)-wage workers sort into high(low)-wage firms. Industries with low ICT intensity do not exhibit these sorting patterns. A labour market matching model explains the increased assortative matching in ICT intensive industries in response to stronger import competition through an increase in the relative demand for qualified workers.

JEL Classification: F16, J63, O33

Keywords: $\quad$ wage inequality, employment dynamics, assortative matching, import competition, technological change

Corresponding author:

Rita Ginja

Uppsala Center for Labor Studies

Department of Economics

Uppsala University

Box 513

SE-751 20 Uppsala

Sweden

E-mail: rita.ginja@nek.uu.se

\footnotetext{
* We thank Aron Berg, Mikael Carlsson, Nils Gottfries, Katariina Nilsson Hakkala, Fredrik Heyman, Francis Kramarz, Renata Narita, Oskar Nordström Skans and anonymous referees for invaluable comments and seminar participants at the Norwegian School of Economics, Riksbanken, Uppsala University, 2014 Nordic Workshop on Matched Data, 2014 Nordic International Trade Seminar, 2015 Barcelona GSE Summer Forum and 2015 SOLE Meetings. The authors gratefully acknowledge financial support from the Wallander-Hedelius-Browaldh Foundation and the Ragnar Söderbergs Stiftelse. The views expressed in this paper are those of the authors and do not necessarily represent the official views of the Central Bank of the Republic of Turkey.
} 


\section{Introduction}

Technology and trade have often been viewed as factors affecting the allocation of labour and resources across firms and industries. In the last couple of decades, technological change has been especially marked by increased diffusion of the information and communication technologies (ICT) across the world. These new technologies have not only changed production processes (Autor and Dorn, 2013) but also affected the demand for different types of labour (Acemoglu, 1999, Caselli, 1999, Katz and Autor, 1999). Contemporaneously, the developments in international trade have mostly been marked by the ascension of China to the largest manufacturing exporter. The rise in Chinese exports was associated with a concurrent decline in manufacturing goods prices, but it also had disruptive effects on the labour markets of other economies, especially among low-skilled workers (see Autor et al., 2013, 2014, 2015, and Balsvik et al., 2015). While the existing literature has studied the role of ICT and trade separately, the evidence on the effects of technology-trade interactions on the allocation of labour across firms has been scarce. We aim to fill this gap in the literature, relying on worker-firm matched data.

In this paper, we study the labour market effects resulting from increased import competition from low income countries, focusing on the case of China, in industries characterised by different ICT intensity 1 To characterise the workers and firms according to their earning/paying potential, we apply the methodology developed by Abowd, Kramarz and Margolis (1999) (hereafter AKM) on detailed administrative matched worker-firm data covering the entire private Swedish manufacturing sector for the period of 1996-2006. This rich data allows us to analyse both the changes in the allocation of workers across different firms as well as their movements in and out of the manufacturing sector.

\footnotetext{
${ }^{1}$ Developed and developing economies specialise in different types of goods or phases in the production processes (Schott, 2004, Baldwin and Lopez, 2015). Import of final goods from low-wage countries creates incentives to the specialization in advanced technologies in developed economies, while import of intermediate goods or task offshoring changes the domestic production processes. Thus, an increase in trade with developing countries may be viewed as a form of technological change in developed economies.
} 
We first segment the manufacturing sector according to the industries' ICT intensity (high/low), based on the classification developed by Van Ark et al. (2003). We then classify industries according to their change in exposure to trade. Since the early 1990s, both Swedish exports and imports have experienced a rapid increase. Following Autor et al. (2013, 2014, and 2015) and Balsvik et al. (2015) we focus on the significant increase in trade with China: $:^{2}$ We classify manufacturing industries according to the change in Chinese imports share (high/low) between the two periods. We define the two periods as two overlapping segments: 1996-2001 (Period 1) and 2000-2006 (Period 2), motivated by China's entry into the WTO in 2001, which we take to be an exogenous trade shock to a small open economy like Sweden.

We show that there were significant changes in the allocation of different types of workers to different firms between the two periods. First, the variance of wages rose by $15 \%$ between the two periods, and, as evidence in line with the type-specific sorting phenomena, $10 \%$ of this change in variance was due to the covariance of person and firm fixed effects. Furthermore, the change in this covariance was different according to the ICT-intensity of industries: it accounted for $18 \%$ of the change in wages in ICT intensive industries, whereas in the group of low ICT intensity industries the covariance was nearly unchanged. Finally, we construct the joint distribution of person-firm wage components to study person and firm type matches within and across periods and industries. This mapping allows us to investigate whether the increased sorting occurs for high/low fixed effects persons and firms, which, as in AKM, we call high/low wage type workers and firms, respectively..$^{3}$

First, we find that type-specific sorting is a phenomenon that appears primarily in ICT intensive industries. That is, these industries faced an increase in the share of low(high)-

\footnotetext{
${ }^{2}$ The trend accelerated after China joined the WTO in 2001. Comtrade data shows that Swedish imports from China grew 20\% annually between 1996 and 2006 and, as in many developed countries, the growth in trade with China represented the bulk of the growth in imports from developing countries. In Sweden it was also the largest increase among its leading trade partners.

${ }^{3}$ Throughout the paper, we refer to person or worker fixed effects interchangeably, since an individual needs to be observed working to compute the fixed effect.
} 
wage persons in low(high)-wage firms between Periods 1 and 2, and a reduction in the share of low-wage persons in high-wage firms. Second, ICT intensive industries exposed to higher increase in Chinese import penetration show a stronger increase in the share of high-wage workers in high-wage firms, while there are no significant changes in the share of low-wage workers in low-wage firms. On the contrary, in ICT intensive industries with a low change in import penetration, increased sorting primarily concerns the share of low-wage workers in low-wage firms. Finally, we do not find any of these sorting patterns in low ICT industries, regardless of their exposure to trade competition.

We then use a simple labour market matching model with both firm and worker heterogeneity to rationalise our empirical findings. The model extends Albrecht and Vroman (2002) by introducing productivity differences across firms within heterogeneous industries. There are two worker types in the model, low-skill and high-skill workers. Firms differ in their productivity and they can post one of two types of jobs: an unqualified job, performed by either a low-skill or a high-skill worker, and a qualified job, which can only be performed by a high-skill worker. The latter jobs are more productive, and ICT intensive industries are characterised by a higher relative productivity of the qualified jobs.

We simulate the impact of exposing a subset of both high and low ICT industries to an increase in import competition. We assume that this reduces the productivity of unqualified jobs in exposed industries. As a result, the least productive exposed firms will exit the market, while firms with higher productivity will upgrade their posts from unqualified to qualified jobs, which results in an increase in employment of high-skill labour (high end sorting). Consequently, low-skill workers leave the exposed industry and their wages decrease. In the non-exposed industries, the number of unqualified jobs increases (low end sorting). In low ICT intensity industries where the relative productivity of the qualified jobs is lower, responses to a trade shock are significantly weaker.

This paper relates to several strands of technological change, trade and labour literature. 
On the one hand, a branch of literature focuses on skill-biased technological change, where firms that use different types of technology employ labour input of different skill levels. ${ }^{4} \mathrm{Au}-$ tor and Dorn (2013) find an increase in the employment share of high- and low-skilled workers relative to the middle-skilled group, which they argue may be linked to the ICT related technology. On the other hand, trade models with heterogeneous firms predict that import competition may cause pressures on low-skilled labour as firms upgrade their skill composition $\sqrt[5]{ }$ Nevertheless, there is little empirical evidence of such link..$^{6}$ Import competition from low-wage countries may cause stronger competitive pressures in the least productive firms, using technologies and producing goods similar to the low-wage country's technology and exports. Several recent empirical studies find that increased Chinese import competition is associated with negative impacts on wages, employment and welfare payment, especially among the low skilled (see Alvarez and Opazo, 2011, Autor et al., 2013, and Ashournia et al., 2014), but do not link these effects to specific firms.

In a recent paper, Autor et al. (2015) attempt to disentangle the effects of two forces the ICT technology and import competition - on employment across different sectors and occupations. They find that technological progress and import competition have rather independent effects 7 We follow a similar approach, but use the worker-firm matched data which allows to control for firm time-invariant characteristics. Besides our work, we are only aware of three other studies which attempt to study the labour market impacts of both trade and technology (Autor et al., 2015, Håkanson et al., 2015, Bloom et al., 2016) $8^{8}$

\footnotetext{
${ }^{4}$ See Acemoglu (1999) and Caselli(1999), among the first. Albrecht and Vroman (2002) arrive at a similar prediction in the model with skill-job type complementarities and unemployment.

${ }^{5}$ For a review of the literature, see e.g. Ashournia et al. (2014).

${ }^{6}$ See e.g. Kugler and Verhoogen (2011), Bas and Berthou (2013). In their theoretical work, Davidson et al. (2008) and Davidson and Matusz (2012) analyse the effect of export and import competition on the choice of technology and the resulting labour market outcomes. They find high end sorting in exporting industries (high skilled workers sort into more productive firms).

${ }^{7}$ Some previous hypotheses regard them as two faces of the same phenomenon. For example, Grossman and Rossi-Hansberg (2008) find that with different countries adding value to global supply chains, the task trade results in productivity effect that benefits the factor whose tasks are more easily moved offshore.

${ }^{8}$ Håkanson et al. (2015) also analyse Swedish data and they find a significant increase in assortative
} 
The choice of Sweden as the country of focus fits the propose for four main reasons. First, the availability of longitudinal data on characteristics of firms and workers allows to study in detail the transitions of workers across firms and in-and-out of the labour market. Second, most of the studies on similar questions use U.S data, which is a large open economy with an independent trade policy. On the contrary, Sweden is a small open economy, a part of the EU and it has limited power in international trade agreements. Therefore, sharp changes in international trade flows, such as Chinese exports to the world, are mostly exogenous shocks to Swedish firms. Third, the period covered by our study (1996-2006) has relatively been political and economically stable. Since 1997, there has been a stable wage setting scheme characterised by collective or local wage agreements in the manufacturing sector, which explain the very low contribution of firms' wage-premium to the change in overall wage inequality (see Nordström Skans et al., 2009). 9 Fourth, we focus our study on manufacturing firms, which represent about 1/3 of the total GDP and occupy just over 1/3 of the total of workers in the Sweden, similar to other EU countries.

The paper proceeds as follows. We present the data sets used in Section 2, we then follow with the empirical strategy in Section 3. In Section 4 we present the empirical results and in Section 5 we present a simple model to rationalise the potential mechanisms behind our findings. Section 6 concludes.

matching. They contrast two potential explanations - offshoring and skill-biased technical change - and find that the latter seems to have been more important. Bloom et al., 2016, study the impact of Chinese import competition on technical change, whereas our focus lies on the impacts of exposure to trade competition on labour allocation according to a broad definition of technology, based on the use of ICT.

${ }^{9}$ Despite changes in the early 1990s in wage setting, Sweden is still characterised by a highly centralised bargaining setting, and $90 \%$ of the employees have part of their pay determined by local negotiations (see http://www.worker-participation.eu/National-Industrial-Relations/Countries/Sweden/ Collective-Bargaining). 


\section{Data}

We use firm- and worker-level data from databases maintained by Statistics Sweden (SCB). We convert all monetary values to 2010 SEK using the Consumer Price Index information from SCB. Information about Chinese trade comes from the UN Comtrade database 10 ICT classifications are based on those set by Van Ark et al. (2003).

\subsection{Firm data}

Firm-level balance sheet data is available from the Account Statistics (Företagsekonomisk Statistik, FEK). We start the analysis in 1996 since the data only covers a selected sample of large companies until that year. The data includes information on sales, exports, profit, capital, number of employees, and industry classification at the firm level. We define industries using the two digit codes 11 We supplement this data with the Business Register Database (Företagsregistret), which includes information on the legal form and controlling ownership of the firm.

\subsection{Worker data}

The matched employer-employee data is gathered by the Swedish Tax Authority (Skatteverket) and it is available in the Register Based Labour Statistics database (Registerbaserad Arbetsmarknadsstatistik, RAMS). This data contains information on total labour earnings collected to compute taxes of all employees. Each individual is linked to a firm (and a plant if applicable) where they were employed in the third week of November, in line with the

\footnotetext{
${ }^{10}$ See http: // comtrade.un.org/

${ }^{11}$ Industry classification code systems in Sweden were updated once during the period studied from SNI1992 to SNI2002. We merge the series at the three digit industry code using the conversion keys supplied by Statistics Sweden where available, and make use of overlapping years in the different code systems to generate our own conversion key if the SCB key does not exist. In the 3 instances where an industry has been split up into several parts, we assign the firms to the new industry whose description best matches the old industry description.
} 
International Labour Organization's definition. For each worker there is information about annual labour income, main place of employment according to the definition stated above, age, gender, and the highest level of education which we use to group individuals into three educational groups: less than high school, high school diploma and some college.

Sample Selection We restrict our data to include manufacturing firms that are active any time between 1996 to 2006. We keep firms with at least 5 employees per year during their entire presence in this range. We restrict our sample to privately owned limited liability partnerships or limited liability companies 12 We further restrict the analysis to workers of 20-65 years of age with a known level of education in each year. As the data does not contain information on hours worked, we restrict the baseline sample to individuals with labour earnings of at least SEK 120,000 a year (SEK 10,000 $\approx$ USD 1,570 a month) to exclude part-timer workers. Finally, we top coded income at the 99th percentile (the results are robust to such top coding) $\sqrt[13]{3}$ More information about the data set can be found in Table A.1 in Appendix A.

\subsection{Trade and ICT Classifications}

Information and Communications Technologies Our measure of ICT adoption follows the classification done by Van Ark et al. (2003) ${ }^{14}$ Based on their classification, we group together the ICT producing and using industries as high ICT intensity industries as they represent a higher rate of ICT adoption than the industries in the non-ICT group which we

\footnotetext{
${ }^{12}$ There are 60,907 firms in the database identified as manufacturing firms in this period. Our restriction of minimum 5 employees drops about 51,000 firms, 72\% of which reported just one employee. These micro-firms are linked to self-employment, which is beyond the scope of our analysis.

${ }^{13}$ The income restriction drops 401,074 employees. Of the workers whose income is below the cutoff, about $26 \%$ of them earned at most a total of SEK10,000 ( $\approx$ USD 1,570) in a year, and about $67 \%$ of them earned at most SEK 50,000 ( $\approx$ USD 7,850) annually.

${ }^{14}$ The classification is based on the U.S., Austria, Denmark, Finland, France, Germany, Ireland, Italy, the Netherlands, Spain, Sweden and the UK.
} 
name as low ICT intensity. Details of the classification can be found in Table A.2 in Appendix A 15

Chinese Import Penetration We use UN Comtrade data for international trade between Sweden and each of its partners. The match between Comtrade data which classifies trade based on product (not industry) and the firm-level data that uses the Swedish industry codes, is based on the description of each product and industry (see Table A.3 in Appendix A.

To define exposure to Chinese trade competition, we construct a measure of Chinese import penetration (CIP), which takes imports from China for industry $k$ in year $t$ as a share of total of imports from the world for industry $k$ in year $t$, that is,

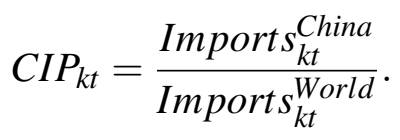

We do this for the years of $t=1996$ and 2001 to obtain the share of Chinese imports to Sweden for each of the 21 industries in the data (see Table 1). As we are interested in capturing the effect of the change in exposure to Chinese imports on labour outcomes, we rank manufacturing industries according to the percentage change in Chinese import penetration between 1996 and 2001. We then define as High Exposure Industries the 10 industries with the largest change in the share of Chinese imports and we define as Low Exposure Industries the 11 sectors with the smallest change in the share of Chinese imports. By focusing on the change within the period before the Chinese accession to the WTO, we do not rely on any simultaneous forces within the second period related to firms repositioning in the market as a response to Chinese imports. As a result, our classification is based on potential growth in exposure to trade.

\footnotetext{
${ }^{15}$ We merge ICT producing and intensive categories into the same group in our classification of high ICT industries. We keep low ICT industries exactly the same as Van Ark et al. (2003). As an alternative, the EU-KLEMS database provides continuous measures of consumption and gross fixed capital formation in ICT assets for the period at hand, however, their higher level of aggregation at the industry level identifies only 13 industries and does not translate to the level of detail we use in our industry-level analysis.
} 
We consider two alternative measures of Chinese import penetration. The first approach takes the median ranking of changes in the first three years in Period 1 to the first three years in Period 2 in ordered pairs (1996 and 2001, 1997 and 2002, and 1998 and 2003) to classify industries as having a low (Low Exposure) or high (High Exposure) change in Chinese import competition. The second alternative ranks industries according to the change from 1996 to 2001 in the share of Chinese imports over domestic production and imports net of exports for each industry, that is, the Chinese imports as a share of apparent domestic consumption. We show in Section 4 that our results are robust to the measure of import penetration used.

\section{Empirical Strategy}

Here we present the basic econometric framework to disentangle the components of wage variation attributable to worker-specific and employer-specific heterogeneity. We follow AKM and Card et al. (2013) in our empirical exercise. We assume that the log real annual labour earnings $y_{i t}$ of individual $i$ in year $t$ can be modelled as an additively separable model of the worker time-invariant characteristics $\alpha_{i}$, a component specific to the firm $j$ where the individual works in year $t$ (denoted $\theta_{J(i ; t)}$ ), a set of time-varying observable characteristics of the individual, $x_{i t}^{\prime} \beta$, and an error component $\varepsilon_{i t}$. Then, we estimate the following model:

$$
y_{i t}=\alpha_{i}+\theta_{J(i ; t)}+x_{i t}^{\prime} \beta+\varepsilon_{i t}
$$

In equation (2), $\alpha_{i}$ subsumes a combination of skills and other time invariant factors specific to the worker $i$ that are rewarded equally regardless of the employer. $x_{i t}^{\prime} \beta$ includes lifecycle components and aggregate shocks that affect a worker's wage in all jobs. In particular, $x_{i t}$ includes year fixed effects and a cubic polynomial on age fully interacted with highest lifetime educational attainment. We consider two indicators of completed education of an individual: 
an indicator for high school degree and an indicator for some college attendance or more (high school dropout is the excluded category). The firm effect $\theta_{J(i ; t)}$ is a proportional wage premium paid by firm $j$ to all employees (for example, rent-sharing) 16

The residual of equation (2) is of particular interest to motivate an additively separable model of workers and firms time-invariant characteristics. We follow Low et al. (2010) and write $\varepsilon_{i t}$ as

$$
\varepsilon_{i t}=\psi_{i J(i, t)}+\phi_{i t}+u_{i t}
$$

where the match effect $\psi_{i J(i, t)}$ represents an idiosyncratic wage premium earned by individual $i$ at firm $j$. We assume that $\psi_{i J(i, t)}$ has mean zero for all $i$ and for all $j$ in the sample interval. The match specific wage component is a productivity component associated with each job match. As it is typical in the earning dynamics literature (see Meghir and Pistaferri, 2004), we assume that $\phi_{i t}$ has mean zero for each person in the sample interval, but it contains a unit root, that captures a drift in the earnings of individuals. Innovations to this component could reflect on-the-job-learning and other unobserved human capital accumulation, promotions/demotions, health shocks, or job mobility. Finally, the transitory component $u_{i t}$ represents any mean reverting factors, such as overtime work, piece-rate compensation and bonuses and premia. We assume that $u_{i t}$ has mean zero for each person in the sample interval.

To study the sorting of workers by type across different firms, we construct the joint distribution of the person and firm effects obtained from the baseline regressions for each of the two periods. We classify industries according to their ICT intensity and the change in

\footnotetext{
${ }^{16}$ Some recent papers criticise the methodology of AKM on the grounds that the economic interpretation of the estimated worker and firm fixed effects is unclear; see Hagedorn et al. (2012), Eeckhout and Kircher (2011) and Lise et al. (2013). In light of this, we see the AKM decomposition into worker and firm fixed effects primarily as a description of the covariance structure of the wages/earnings. We do not take a stand on the underlying economic factors (complementarities, matching, individual and collective bargaining, etc.) that generate these correlations.
} 
their exposure to Chinese import competition as explained in Section 2, and then we track the changes in the joint firm-worker effects distribution between Period 1 and Period 2.

Estimation and assumptions about $\varepsilon_{i t}$ We estimate equation (2) by OLS. The firm fixed effects in equation (2) are identified by individuals who move between firms and generate a large network of firms in which each firm is tied to at least one another firm in the group through at least one worker who moves between them. We construct the largest of such networks of interconnected workers and firms in each period, which we call the mobility group, and restrict our analysis to this group of firms (see Abowd et al., 2002). Table A.4 in Appendix A shows that the largest group includes at least $91 \%$ of the firms and $99 \%$ of all the workers. Table A.4 in Appendix A shows that there are 865,674 and 890,704 identifiable fixed effects in Periods 1 and 2, respectively. ${ }^{17}$

Abowd et al. (2004) show that the estimated fixed effects may not be precisely estimated if few workers switch between firms; a problem that they call "limited mobility bias". To address this issue the analysis is repeated on two separate samples of firms where the minimum number of movers between firms are restricted to at least 5 (the main sample) and at least 10 (alternative sample). Our conclusions below are not altered by using this stricter mobility group (results available from the authors).

The person and firm fixed effects in equation (2) are identified by OLS if the three components in $\varepsilon_{i t}$ are (a) orthogonal to the individual and firm fixed effects and (b) if they are orthogonal to the year fixed effects and to the cubic polynomial on age interacted with maximum educational attainment. The assumption (b) is standard, whereas assumption (a) holds since the hypotheses for $\psi_{i J(i, t)}, \phi_{i t}$ and $u_{i t}$ stated above ensure that $\varepsilon_{i t}$ is orthogonal to the individual fixed effects $\alpha_{i}$. Note that by conditioning on individual fixed effects $\alpha_{i}$ and on

\footnotetext{
${ }^{17}$ We focus on firm fixed effects, rather than plants, as $85 \%$ of the firms in the Swedish manufacturing sector only have one plant (the results below remain unchanged if we focus on plant-level fixed effects; such results are available from the authors).
} 
$\theta_{J(i ; t)}$, we allow for the systematic mobility of workers across firms to be correlated with individual time invariant characteristics and firm specific wage-premia; for example, we allow high-wage workers to be more likely to move across firms. However, $\varepsilon_{i t}$ may not be orthogonal to the firm fixed effects, since there are forms of endogenous mobility that could bias the estimate of firm fixed effects. In section 4.4 we show that endogenous mobility does not pose a threat to identify the firm fixed effects.

\section{Results}

For our analysis, we divide the data into two overlapping periods. Period 1 is defined as the years before the Chinese membership in the WTO (1996-2001) and Period 2 as the postChinese membership years (2000-2006).

\subsection{Characteristics of the Workers and Firms}

Table 2 shows basic characteristics for the individuals in our sample for the first and last years in the data (1996 and 2006). The sample is on average 40 years old, and almost $80 \%$ are males. Panel A shows that in 1996 a fifth of the workers have attended some college, but almost a third do not have a high school degree; by 2006 this proportion decreases to $19 \%$. Panels B and C show that a quarter of high ICT workers have attended college, compared to $16 \%$ in low ICT. Despite this difference, over the years high and low ICT faced a similar relative increase in the share of workers with some college.

In Table A.5 in Appendix A we turn to a more detailed look at some basic characteristics of each industry grouped according to our ICT and import competition definitions. The table summarises for 1996 and 2006 the share of total employment, the share of workers who attended some college, the average number of workers per firm, and the number of firms for each industry. The table shows that the share of employment is rather evenly distributed 
across the four groups of industries in the table, however the machinery and equipment industry (high China-high ICT; Panel D), motor vehicles and trailers (low China-low ICT; Panel A) and fabricated metal products (high China-low ICT; Panel C) stand-out as they employ between $9-16 \%$ of the overall manufacturing employment each. Industries classified under low China-high ICT (Panel B) employ a smaller share of the total manufacturing employment, at around $15-17 \%$. The share of workers with at least some college education is about 20\% and similar in three groups of industries (low China-low ICT in Panel A; low China-high ICT in Panel B, and high China-high ICT in Panel D), but the group of industries in Panel C (high China-low ICT) stand out with the lowest average share of college worker per firm at just 12\% in 1996 (16\% in 2006). Between 1996 and 2006, all industries increased the share of workers with some college, with the largest mean increase across the four type of industries in low China-high ICT industries (Panel B) ${ }^{18}$ The average firm size varies considerably within each industry in the four groups. Finally, the last set of columns presents the number of firms by industry, which decrease in all four groups. The largest decline in the number of firms occurred in high ICT industries (panels B and D of the table).

\subsection{Variance Decomposition}

The model of wage determination presented in equation 2 explains 87 and $88 \%$ of the variation in annual log earnings in each period, respectively. To quantify the contribution of person and firm effects for the change in inequality we decompose the variance of observed log earnings $\left(y_{i t}\right)$ for workers in each time interval as:

\footnotetext{
${ }^{18}$ The share of workers that attended some college increased on average by $36 \%$ in the low China-low ICT (Panel A), by 53\% in the low China-high ICT industries (Panel B), by 47\% in the high China-low ICT (Panel C) and by $25 \%$ in the high China-high ICT industries (Panel D).
} 


$$
\begin{aligned}
\operatorname{Var}\left(y_{i t}\right)=\operatorname{Var}\left(\alpha_{i}\right) & +\operatorname{Var}\left(\theta_{J(i ; t)}\right)+\operatorname{Var}\left(x_{i t}^{\prime} \beta\right)+2 \operatorname{Cov}\left(\alpha_{i}, \theta_{J(i ; t)}\right) \\
& +2 \operatorname{Cov}\left(x_{i t}^{\prime} \beta, \theta_{J(i ; t)}\right)+2 \operatorname{Cov}\left(\alpha_{i}, x_{i t}^{\prime} \beta\right)+\operatorname{Var}\left(\varepsilon_{i t}\right) .
\end{aligned}
$$

Table 3 presents the decomposition for each period for the full sample and by ICT intensity. Between Period 1 and 2 the variance of earnings increased 15\%. The rise in the variance of the person component contributed to $45 \%$ of the overall increase in the variance of earnings, whereas the increase in the variance of the firm component contributed only to $2 \%$ of the change in the variance in earnings 19 The rise in the covariance between the firm and person time invariant components contributes to $10 \%$ of the change in wage inequality in the period studied (that is, the term $2 \operatorname{Cov}\left(\alpha_{i}, \theta_{J(i ; t)}\right)$ ).

There are remarkable differences by industry type. The split by industry-type on the right hand side of the table shows that the increase in the variance of earnings in ICT intensive industries was larger than it was in low ICT industries (19\% and $11.6 \%$, respectively). The change in the variance of person effects contributed to $50 \%$ and $40 \%$ of the overall change in earnings inequality in ICT intensive and low-ICT industries, respectively. Finally, the change in the covariance between person and firm fixed effects contributed to $18 \%$ of the change in the earnings in ICT intensive industries, whereas in low-ICT industries the contribution of the covariance of firm and person components remained nearly unchanged. This difference in the change in the covariance between worker and firm effects by sector motivates a detailed study of workers allocation across firms between 1996 and 2006.

\footnotetext{
${ }^{19}$ Card et al., 2013, document that the increase in the variance of the firm component for Germany contributes to $25 \%$ of the change in wage inequality. However, they focus on a male-only sample and use a longer interval than our study.
} 


\subsection{Changes in the Distribution of Workers and Firms between 1996 and 2006}

To illustrate the sorting of workers into different types of firms we map the joint distribution of the person and firm effects obtained from estimating equation 2 for each period. We first rank the firm and person effects, and then group them into deciles. Each bin contains 10\% of all person and firm fixed effects for each worker, which implies that we effectively weight the firm fixed effects by the number of workers in each firm. Next, for each firm and person effect decile bin intersection, we calculate the share of worker-year matches to firms that fall into that particular bin, as a share of total possible firm-worker-year outcomes in the period. This is represented by the height of a bar in the graph. Within each period, the sum of the shares adds up to $100 \%$. This ranking allows us to focus on the relative positioning of the firm and person effects compared to the pool of other workers and firms rather than the absolute value of these effects. We are, in other words, focusing on the shape of the joint firm-worker effects distribution.

Figure 1 presents the joint distribution of the worker-firm effects in the two periods (top left: 1996-2001, top right: 2000-2006) and the difference (bottom panel) in the share of workers in each worker-firm bin between the periods. The difference graph in the bottom panel of the Figure shows that the bottom and top paying deciles of firms do not exhibit any change in the share of workers. However, in the remaining ranges of firm types, we observe positive sorting, that is, an increase in the mass of workers in the bins associated to the combination high wage-worker and high-wage firms (on the top-right quadrant of the Figure in the bottom panel). There are also overall losses in the employment shares of the middle deciles of the firm effect (bins 5 and 7) 20

\footnotetext{
${ }^{20}$ In Figure B.1 in the Appendix A we present the dissection of the distribution for the total period by education as: (1) high school and dropouts and (2) workers with some college. The figure shows that high school workers are distributed more or less evenly across the whole support of the worker-firm effects, with some degree of positive assortative matching on both ends. College workers, on the other hand, concentrate in
} 
We now turn to the changes in allocation for the two broad ICT groups. Panel A of Figure 2 shows that within low ICT intensity industries there are barely any changes in the joint distribution of firm and worker type. In turn for ICT intensive industries there are pronounced changes from Period 1 to 2 (Panel B). There is a large increase in the share of low-wage workers in low-wage firms, and a reduction in their shares in high-wage firms. Simultaneously, the share of high-wage workers in high-wage firms increases. Although this finding may be in line with the theoretical predictions of the skilled-biased technological change literature, the reallocation pattern may not occur uniformly within ICT group. In particular, trade with developing countries whose technologies and/or final products may be similar to those produced by some industries in Sweden, may be associated with differential changes across and within the ICT groups, which we exploit next.

Technology and Import Competition Interactions We now focus on ICT intensive industries and allow for differential changes according to exposure to different degrees of competition from China. Panels A and B of Figure 3 show the joint distribution of workersfirms fixed effects for ICT intensive industries according to their exposure to trade with China. In ICT intensive industries with a high change in Chinese import penetration (Panel A) there is an increase in the share of high-wage workers in high-wage firms. There are no significant changes on the low end of the distribution. We view this result as an indication of the joint contribution of the two forces in skill upgrading of high quality firms, while leaving employment shares at the low end of the distribution unchanged.

Panel B of Figure 3 shows that in ICT intensive industries with a low change in Chinese import penetration there is an increase in the share of low-wage workers in low-wage firms. There are also smaller changes in the share of high-wage and low-wage workers in highwage firms. This pattern resembles the aggregate results in ICT intensive industries, but with

the highest paying firms and a large share of these workers are also high-wage individuals. 
a smaller change at the high end, and a larger change at the low end of the firm distribution. The increase in the share of low-wage employment at the low end of the firm distribution indicates that these types of firms, in industries with less exposure to import competition, may have served as shelter firms $\sqrt{21}$ We do not observe the similar "shelter" effects in nonexposed low ICT intensity industries (see Panel B of Figure B.2 in the Appendix B), where the distribution remains unchanged across periods, regardless of the degree of exposure to Chinese import competition.

To quantify the patterns described in our graphical analysis, we divide the plane of worker and firm effects into low (bins 1 through 5) and high (bins 6 through 10) areas, giving us 4 quadrants: Low Firm-Low Person, Low Firm-High Person, High Firm-Low Person, and High Firm-High Person. In Table A.6 we present the marginal effects from estimates of a multinomial logit model. The dependent variable has four categories correspondent to each one of the quadrants described. We include controls for firm and worker characteristics such as year fixed effects, gender of the worker, highest completed education, age, tenure in firm, firm's characteristics (capital per worker, profit per worker, and share of high school and college graduates on the firm side), and levels and interactions between of the degree of Chinese import penetration and ICT which are not reported in the table. Column 1 of Table A.6 shows that, compared to the "High China-High ICT" scenario, all the three other combinations of degrees of competition from China and ICT levels are more likely to have a Low Firm-Low Person outcome in Period 1. Low China-High ICT industries are most likely to produce an Low Firm-Low Person outcome in Period 2, which is consistent with the graphs in panel B of Figure 3 that show positive sorting on the low end for this group of industries. On the other hand, column (4) shows that all industries are less likely to produce a High Firm-High Person outcome compared to High China-High ICT industries, and again these differences become even more pronounced in Period 2 relative to Period 1.

\footnotetext{
${ }^{21}$ We find similar patterns using alternative definitions of exposure to import competition; see Figures B.3. B.4 in the Appendix.
} 
Mobility: Origin and Destination Table 4 presents the movements of individuals into different industry and firm groups in Period 2 relative to their industry group in Period 1. The table presents row-percentages (ie, the rows add up to 100\%), which are the shares of individuals per industry group in Period 1 (see Table A.7 in Appendix for the number of individuals in each cell). The sample used to construct this table is restricted to those individuals and firms used in our main analysis. We group industries according to their ICT intensity and changes in exposure to import competition from China in Periods 1 and 2. The table has four horizontal panels (Panels A-D) where individuals are grouped into four possible groups (LFLP, LFHP, HFLP, HFHP) according to their position in Period 1. The two first letters denote the firm type and the two last letters denote the person type. Excluding the marginal bins (5 and 6); "LF (HF)" is a firm with fixed effects in bins 1-4 (7-10) of Figure 1 in Period 1 and "LP (HP)" is a person with fixed effects in bins 1-4 (7-10) of Figure 1 in Period 1. Since individual effects are stable over the whole period for workers present in both Periods 1 and 2, we use the type of individual as of Period 1 (note that our interest lies in studying the transition of individuals across firm types and in and out of the manufacturing sector).

Within manufacturing, individuals may switch jobs across industries within each period (ie, within Period 1 and Period 2), thus we assign each individuals firm type as the last affiliation of employment within each period. Individuals in column "Switch" are those that were employed in a manufacturing job in Period 1, but switched to a non-manufacturing job in Period 2. For individuals in column "Exit" we do not observe any work related income for the whole of Period 2, in neither manufacturing nor non-manufacturing industries and we consider them as having exited the sample which could be due to a leave to unemployment or the labour force altogether, retirement or death, as well as due to our sample selection (an income below the income restriction of 120000SEK/year in Period 2, or aging beyond 65 years). "Stayers" are individuals present in Periods 1 and 2. "Newcomers" are individuals 
who were not in our sample in Period 1 (either because they did not meet the income restriction, were younger than 20 years old, were out of the labour force, unemployed or working outside the manufacturing sector), but who enter the manufacturing sector in Period 2.

The second row in column (8) of Panel D shows that in ICT intensive industries, $26.4 \%$ of high skill labour in low-wage firms in industries with a large increase in the share Chinese of imports is reallocated to high-wage firms within the same industries. In the group of low ICT intensity industries group this effect is weaker, $14.8 \%$ (see the second row in column (4) of Panel B). Simultaneously, 25.3\% of low skill labour in low-wage firms in industries with a high increase in import competition is reallocated to low-wage firms in industries not exposed to the trade shock (first row of column (5) in Panel D).

Panel A ("Low ICT-Low China") of the table presents the largest proportion of switchers out of manufacturing sector, whereas in "High ICT" industries (Panels C and D), the switching out of manufacturing (but not exit) is relatively uniform across persons and firms types, regardless of the exposure to import competition from China. The row that refers to "Stayers" shows that the largest share of individuals present in Periods 1 and 2 corresponds to industries classified as "Low ICT-Low China" (columns (1) and (2)). One the other hand, exit rates are more or less uniform across industry types (see column (10)). As expected, Panel D ("High ICT-High China") shows the highest rate of leavers is among low-wage workers in low-wage firms and the smallest among high-wage workers in high-wage firms in Period 1.

\subsection{Assessing the Empirical Strategy}

Endogenous Mobility Here we assess whether endogenous mobility of workers across firms may invalidate the identification of firm fixed effects. First, individuals may sort into firms based on an individual worker-firm match component $\psi_{i J(i, t)}$. To address this concern, we estimate a fully saturated model, which includes an indicator variable for each individual- 
job combination. The fully saturated model explains $90 \%$ and $89 \%$ of the variation in $\log$ earnings in the Periods 1 and 2, respectively, as opposed to $88 \%$ and $87 \%$ explained by the double fixed effect model. This shows that the improvement in the fit with the individual-job match model is relatively small compared to our baseline specification which is additive on firm and worker fixed effects.

Second, $\phi_{i t}$ will be correlated with the firm fixed effects if wage growth predicts transitions across jobs. In other words, if permanent shocks to wage growth are correlated with job-to-job transitions. To address this concern, we perform a basic event-study as suggested in Card et al. (2013). In particular, we study the change in the mean earnings of workers who change jobs within each interval and who were employed in their old and new firms for two years in a row before and after the switch. We then classify the firms into high- and lowpaying firms based on the mean earnings of co-workers. Figures B.5 and B.6 in Appendix present the change in the mean average earnings by type of firms for individuals who switch firms within Period 1 and Period 2. These figures show that there was no pre-switch trend in the earnings of workers who leave either high- or low-pay firms, regardless of the type of firm where they end up.

Finally, if $u_{i t}$ is correlated with job-to-job transitions, firm fixed effects will be biased. In particular, there will be attenuation bias if individuals facing positive (negative) transitory income shocks are more likely to move to high (low) wage firms. By using the same eventstudy described above, we can address this concern. For both Periods 1 and 2 we are unable to detect a dip or a jump in period -1 for the earnings of workers who leave either high- or low-pay firms independently of the type of firm in which they end up. Then, it is likely that transitory shocks are not correlated with job-to-job transitions 22

\footnotetext{
${ }^{22}$ We do not plot the means for the period of job switch since we do not have information about the exact timing of the switch to assign to the old and new job the corresponding fraction of earnings.
} 
Worker and Firm Fixed Effects Across Periods To assess if worker and firm fixed effects switch rank for individuals and firms present in our sample across the two periods, we plot in Figure B.7 the joint distribution in Period 1 and 2 of effects for workers (panel A) and firms (panel B). The figure does not show significant transitions of workers across different person effect deciles. There is more variability across deciles of firms effects ${ }^{23}$

Furthermore, to understand to which extent the firm fixed effects correlate with observable characteristics, we regress the estimated fixed effects on a set of firm characteristics. In particular, we take one observation per firm and we correlate the firm estimated fixed with the average firm's capital intensity (log capital per worker), exporter intensity, log profits per worker, share of high school graduates and the share of college graduates in the labour force of the firm. After controlling for industry indicators, all of these variables correlate positively with the firm fixed effects, except export intensity ${ }^{24}$ This suggests that both worker and firm effects are a reasonably stable representation of their earning and paying unobserved potentials (i.e. their skills and productivity).

\section{Theoretical Framework}

\subsection{Setup}

In this section, we present a model to rationalise the observed industry dynamics and labour market outcomes. We compare the relative changes in employment across industries in reaction to an increase in import competition in the model simulation and in the data. We rely on a simple labour market matching model with firm and worker heterogeneity based on Albrecht and Vroman (2002) to which we introduce productivity differences across firms

\footnotetext{
${ }^{23}$ The variability of firms fixed effects across periods decreases when we restrict the sample to firms where the minimum number of movers between firms is of at least 10 workers.

${ }^{24}$ Since information on exports of firms is only available after 2000 , we performed this inspection only for the second period in our sample; results available upon request.
} 
within industries.

We assume two types of workers that differ in the skill level. Both live forever and are risk neutral. We normalise the population measure to 1 and assume that a fraction $p$ of the population has low skill of level $s^{1}$, while a fraction $(1-p)$ has a high skill level $s^{2}$.

There are two ex-ante identical industries $k$, where $k=T, N$. One of the industries $(T)$ faces an import shock and we study the changes in the affected industry, as well as the implications for the neutral industry $(N)$ and potential cross-industry reallocations. There is a measure $z^{\max }$ of firms in each industry. Firms differ in productivity, each taking up a productivity value $z$ (which we use to index the firms) from a uniform distribution in the range $\left[0, z^{\max }\right]$. Each firm is represented by one job position and it may choose between two types of jobs, an unqualified or a qualified job. There are minimum skill requirements for each job type: $y_{k}^{1}$ for the unqualified and $y_{k}^{2}$ for the qualified job, respectively, with $y_{k}^{2}>y_{k}^{1}$. When a job in industry $k$ is filled, the resulting output $f\left(s, y_{k}, z_{k}\right)$ is a function of worker's skill $s$, job skill requirement $y_{k}$ and firm productivity $z_{k}$, and is given by

$$
f\left(s, y_{k}, z_{k}\right)= \begin{cases}y_{k}^{\alpha} z_{k} & \text { if } s \geq y_{k} \\ 0 & \text { if } s<y_{k}\end{cases}
$$

where $0<\alpha<1$. The skill requirement is the skill input of the hired worker and it cannot be higher than the worker's own skill level. If producing, firms pay their worker a wage $w\left(s, y_{k}, z_{k}\right)$ and incur a fixed cost $c\left(y_{k}\right)$. The same fixed cost is incurred when the job is vacant. While the fixed cost is higher for qualified jobs, it is the same across industries (i.e. $\left.c\left(y_{k}^{1}\right)=c^{1}<c\left(y_{k}^{2}\right)=c^{2}\right)$. Firms choose the job skill requirements to maximise the value of the vacancy, and they require $y_{k}^{1}=s^{1}$ and $y_{k}^{2}=s^{2}$ for the two job types, respectively. For the unqualified jobs, firms hire workers of any skill and have output $\left(s^{1}\right)^{\alpha} z$, but for the the qualified jobs they hire only high-skill workers, resulting in output $\left(s^{2}\right)^{\alpha} z$. Filled jobs break up at an exogenous rate $\delta$. 
The labour market is not segmented and open jobs and unemployed workers meet randomly. The matching function can be expressed as $m(\theta) u$, where $\theta=v / u$ is the labour market tightness as the ratio of unemployment rate $(u)$ and number of vacancies $(v){ }^{25}$ Lowand high-skill workers meet vacancies at the rate $\phi m(\theta)$ and $m(\theta)$, respectively, where $\phi$ is the share of vacancies that accept the low-skill worker. Likewise, unqualified and qualified vacancies meet unemployed workers at the rate $m(\theta) / \theta$ and $(1-\gamma) m(\theta) / \theta$, respectively, with $(1-\gamma)$ as the share of high-skill workers in the pool of unemployed.

Following Albrecht and Vroman (2002), we define the value functions for employed and unemployed workers (for each type), and for filled and unfilled vacancies (see Appendix C.1 for the detailed specification). The value functions are standard, with the added distinction between $z$-types of firms. The wages for each industry, job type, firm and worker type are determined by Nash bargaining (see Appendix C.1) where the two types of workers and $z$-types of firms imply both within and across skill wage variation.

We focus on the steady state where the flows into and out of unemployment must be equal for each type of workers. Thus, for the low- and the high-skill, we obtain

$$
\begin{aligned}
\delta(p-\gamma u) & =\phi m(\theta) \gamma u \\
\delta((1-p)-(1-\gamma) u) & =m(\theta)(1-\gamma) u .
\end{aligned}
$$

The flows into and out of vacancy pools are equal for each type of vacancy (unqualified and qualified, respectively) and given by

$$
\begin{aligned}
\delta\left(z_{k}^{2}-z_{k}^{1}-v_{k}^{1}\right) & =\frac{m(\theta)}{\theta} v_{k}^{1} \\
\delta\left(z^{\max }-z_{k}^{2}-v_{k}^{2}\right) & =(1-\gamma) \frac{m(\theta)}{\theta} v_{k}^{2} .
\end{aligned}
$$

\footnotetext{
${ }^{25}$ We assume $m(u, v)$ has constant returns and $m^{\prime}(\theta)>0$ and $\lim _{\theta \rightarrow 0} m(\theta)=0$, as well as $\lim _{\theta \rightarrow 0} \frac{m(\theta)}{\theta}=\infty$.
} 
There are two productivity thresholds in each $k$-industry given by $z_{k}^{2}$ and $z_{k}^{1}$. The qualified job cutoff productivity $z_{k}^{2}$ represents the lowest productivity firm opening the qualified vacancy, and the exit cutoff productivity $z_{k}^{1}$ stands for the lowest productivity firm operating. The two conditions above define the number of each type of vacancies $\left(v_{k}^{1}\right.$ and $\left.v_{k}^{2}\right)$ across the two industries as the functions of labour market tightness $\theta$ and the productivity thresholds. Note that $v_{N}^{1}+v_{T}^{1}+v_{N}^{2}+v_{T}^{2}=v=\theta u$ (see Appendix C.1).

Finally, in each industry we define the remaining two steady state conditions for the cutoff productivity that determine the entry and exit of firms in industry $k$, firms that open unqualified jobs, and firms that open the qualified jobs in equilibrium. If the value of unqualified vacancy is larger than the value of qualified vacancy for lower $z$ firms, the marginal exiting firm $z_{k}^{1}$ in industry $k$ is such that the value of opening the unqualified vacancy equals zero,

$$
V\left(y_{k}^{1}, z_{k}^{1}\right)=0
$$

At higher productivity, there exists a firm $z_{k}^{2}$ for which the values of opening an unqualified and a qualified vacancy are equal: ${ }^{26}$

$$
V\left(y_{k}^{2}, z_{k}^{2}\right)=V\left(y_{k}^{1}, z_{k}^{2}\right)
$$

We use the equilibrium conditions for unemployment flows (6) and 7), vacancy flows $(8$ and 9), and the productivity cutoff conditions for each industry $k$ (10) and 11] to solve for the eight equilibrium variables: unemployment rate $u$, labour market tightness $\theta$, the share of unqualified vacancies $\phi$, share of low-skill workers in unemployment pool $\gamma$, industry exit cutoff productivity $z_{k}^{1}$ and the industry job-type cutoff productivity $z_{k}^{2}$.

\footnotetext{
${ }^{26}$ Figure B.8 in Appendix B illustrates these productivity cutoffs.
} 
Increase in Chinese import penetration Following our empirical analysis, we study the effect of a change in Chinese import penetration within the group of ICT intensive industries. ICT intensive firms differ from the low ICT intensity group by their higher return to skill in the production function, $\alpha$. We expose one of the two ex-ante identical ICT intensive industries, industry $T$, to an increase in import competition by assuming a decrease in the productivity of the unqualified jobs in the industry, $\left(y_{T}^{1}\right)^{\alpha}$. A stronger Chinese presence in the industry substitutes the local unqualified jobs. i.e. it lowers their productivity rendering them less valuable, while it leaves the productivity of the qualified jobs unchanged. The results of the numerical exercise are presented in the following section.

\subsection{Numerical analysis}

\subsubsection{Model parameters}

We set most of the model parameters based on their empirical counterparts and calibrate the remaining ones to match a few aggregate data moments. First, we set the values of 7 parameters $\left(r, p, \beta, \delta, b, z^{\max }, \alpha\right)$ and the form of the matching function $m(\bullet)$. The parameter $\alpha$ measures the returns to skill in the production function. We vary $\alpha$ to represent the difference in ICT intensity across industries, where high $\alpha$ represents ICT intensive industries. We calibrate the relative skill $s^{2} / s^{1}$ and the relative vacancy cost $c^{2} / c^{1}$ to match labour market tightness and the unemployment rate in the Swedish data. The summary of the parameter values is presented in Table A.8 and the calibration details are explained in Appendix C.2.

\subsubsection{Numerical results}

In the first numerical exercise, we set $\alpha$ high and reduce $y_{T}^{1}$ to represent an increase in Chinese import penetration in industry $T$ of ICT intensive industries. Below we summarise the main effects. Figure 4 illustrates the effects on each industry's equilibrium variables and 
wages of different worker types on different types of jobs. The solid and dashed lines in the figure refer to the non-exposed $(N)$ and exposed $(T)$ industries, respectively.

Results $A$ decline in the unqualified job productivity in industry $T$ produces the following effects:

1. The level of the productivity cutoff changes. The exit cutoff $z_{T}^{1}$ rises, since now only more productive firms find it optimal to operate the unqualified vacancies. Unemployment rate and the share of low-skill workers in unemployment rise. Consequently, labour market tightness falls making the qualified job vacancies relatively more valuable which reduces the productivity cutoff of the qualified job, $z_{T}^{2}$. A higher share of low-skill workers in unemployment raises the profitability of unqualified jobs in industry $N$, given that their productivity is unchanged. Thus, $z_{N}^{1}$ falls while $z_{N}^{2}$ increases.

2. Due to cutoff productivity movements, the share of low-skill employment in low productivity firms (unqualified jobs) in $T$ industry decreases, while it rises in industry $N$. On the other hand, the share of "high skill-qualified job" type employment in $T$ industry increases, while it decreases in industry $N$.

3. Total employment drops in industry $T$ and it increases in industry $N$.

The average wage at qualified jobs in industry $T$ falls due to lower average productivity. However, for a given range of high $z$ firms, the average wage increases as the value of the outside option of high-skill workers (the value of being unemployed) rises. The average wage of low-skill workers falls. In industry $N$, the movements are the opposite: the average wage of qualified jobs rises due to higher average productivity of these jobs. However, for a given range of high $z$ firms, the average wage at qualified jobs falls. With the decrease of $z_{N}^{1}$ and increase of $z_{N}^{2}$, the decrease in average wage of low-skill at unqualified jobs is relatively smaller than in industry $T$. 
Tables A.9 and A.10 in the Appendix summarise the quantitative effect of a 1\% decrease in $\left(y_{T}^{1}\right)^{\alpha}$ on employment shares and wages across skills in the two industries, and also report their empirical counterparts. To match the changes in the share of high and low skill workers in high and low wage firms in the model and in the data we the following. In the data, we define low (high) skill workers as those workers who in each period have an estimated individual effect in the bottom (top) 40 percent of the distribution of person effects. We then compare the changes in the share of low (high) skill workers on the bottom (top) 40 percent of jobs (i.e. jobs in the low (high) paying firms) in industry $k$.

The model counterparts of low and high skill are given by the workers skill levels, $s^{1}$ and $s^{2}$. The low and high paying firms are distinguished by the job type, $y^{1}$ and $y^{2}$. The model employment shares are then calculated as the shares of different skills, $s^{1,2}$, at different firms/jobs, $y^{1,2}$, in the total industry employment ${ }^{27}$

In the model and the data, we observe an increase in the share of high-skill employment in the high paying firms in exposed industry $T$, both absolute and relative to low-skill employment in the low paying firms. In the non-exposed industry $(N)$, the share of low-skill employment in the low paying firms increases, absolute and relative to high-skill employment in the high paying firms. The model results confirm the observed right tail and left tail sorting in the exposed and non-exposed industries, respectively, within in the group of high ICT intensity industries.

Within and across industry reallocations In the model simulations, the loss in low-skill employment in industry $T$ is compensated by the increase in low-skill labour in industry $N$, hired for unqualified jobs. The new qualified jobs in industry $T$ compensate the loss in high skill employment in unqualified jobs from firms that exit industry $N$. They also absorb the high-skill labour from the firms in industry $N$ that had switched to unqualified jobs.

\footnotetext{
${ }^{27}$ For robustness, we provide the results for two alternative measures of the model firm characteristics in Appendix C.3
} 
Therefore, the model supports increased within industry sorting at the high end in the industry affected by increased import competition, and the reallocation across industries of low-skilled workers to unqualified jobs in industries that are not affected by the trade shock. The empirical evidence on the within and across industry labour reallocation is reported in Table 4 shows dual movements among ICT-intensive firms facing stronger import competition. On one hand, high-wage workers in low-wage firms in the industries reallocate to high-wage firms within the same industries. On the other hand, low-wage workers in lowwage firms reallocate to low-wage firms in industries not exposed to the trade shock. 28

Varying ICT intensity Next, we analyse the effects of an increase in Chinese import penetration in low ICT industries. We use the same two-industry framework ( $N$ and $T)$, but with a lower value of $\alpha$, to capture low ICT intensity. Lower $\alpha$ industries exhibit a lower return to any skill, and also a lower relative return of high to low skill compared to high $\alpha$ (high ICT intensity) industries. This represents a lower relative benefit of hiring a high skill worker to complement the present low ICT technology.

To represent an increase in Chinese import penetration, we reduce the productivity of unqualified jobs in industry $T\left(y_{T}^{1}\right)$ within the two low ICT intensity industries, leaving the jobs productivity in industry $N$ unchanged. The changes in the employment shares under different values of $\alpha$ are presented in Table A.11. With lower $\alpha$, the output reacts less to changes in job productivity. Thus, the exit and job choice of firms are less sensitive to the variation in unqualified jobs productivity (see Appendix C.4 for details). Changes in the employment shares are less pronounced. These results point to the interactions of the ICT technology and Chinese import penetration.

\footnotetext{
${ }^{28}$ One interesting empirical fact, which we do not capture in our theoretical framework, reveals that between Period 1 and Period $236 \%$ of low-wage labour in low-wage firms in low ICT intensity industries with a high change in import competition reallocates to the low-wage firms in high ICT intensity industries with low changes in Chinese import penetration (see the first row of column (5) in Panel B).
} 


\section{Conclusion}

We study the labour market dynamics in the manufacturing sector in a context of increased import competition using detailed matched worker-firm data from Sweden for the period of 1996 to 2006. We focus on the worker-to-firm sorting phenomena in response to the increase in Chinese import penetration due to the ascension of China in 2001 to the WTO in industries with different technology. Technology is measured by the intensity of ICT adoption in a given industry.

We find that in ICT intensive industries there is dual reallocation as a result of exposure to import competition. On one hand, in industries facing strong import competition from China, high-wage workers in low-wage firms reallocate to high-wage firms in the same group of industries. One the other hand, low-wage workers in low-wage firms in industries facing strong import competition from China reallocate to low-wage firms in non-exposed industries, that is, ICT intensive industries with a low change in the Chinese import penetration "shelter" the low-wage workers. Low ICT industries do not exhibit such sorting patterns. These novel findings highlight the role of technology and workers' unobserved wage-type in the re-distributional implications of trade. In addition, they show that there is a higher degree of mobility within and across ICT intensive industries relative to low ICT industries.

\section{References}

[1] Abowd J.M., Kramarz F., and Margolis D.N., 1999. "High Wage Workers and High Wage Firms", Econometrica, 67(2), 251-334.

[2] Abowd J.M., Kramarz F., Lengermann P., and Perez-Duarte S., 2004. ”Are Good Workers Employed by Good Firms?: A Test of a Simple Assortative Matching Model for France and the United States", CREST,mimeo.

[3] Abowd J.M., Robert H. Creecy, and Francis Kramarz, 2002. "Computing Person and Firm Effects Using Linked Longitudinal Employer-Employee Data”, Longitudi- 
nal Employer-Household Dynamics Technical Papers 2002-06, Center for Economic Studies, U.S. Census Bureau.

[4] Acemoglu D., 1999. "Changes in Unemployment and Wage Inequality: An Alternative Theory and Some Evidence", American Economic Review, 89(5), 1259-1278.

[5] Albrecht J. and Vroman S., 2002. "A Matching Model with Endogenous Skill Requirements", International Economic Review, 43(1), 283-305.

[6] Alvarez R. and Opazo L., 2011. "Effects of Chinese Imports on Relative Wages: Microevidence from Chile", Scandinavian Journal of Economics, 113(2), 342-363.

[7] van Ark B., Inklaar R., and McGuckin R. H. 2003, " 'Changing Gear' Productivity, ICT and Service Industries: Europe and the United States", in: Christensen, Jens F. and Maskell, Peter (eds.), The Industrial Dynamics of the New Digital Economy, Edward Elgar, Cheltenham, 56-99.

[8] Ashournia D., Munch J., and Nguyen D., 2014. "The Impact of Chinese Import Penetration on Danish Firms and Workers", IZA Discussion Paper No. 8166.

[9] Autor D. and Dorn D. 2013, "The Growth of Low Skill Service Jobs and the Polarization of the U.S. Labor Market", American Economic Review, 103(5), 1553-1597.

[10] Autor D., Dorn D., and Hanson G., 2013. "The China Syndrome: Local Labor Market Effects of Import Competition in the United States", American Economic Review, 103(6), 2121-2168.

[11] Autor D., Dorn D., and Hanson, G., 2015. "Untangling Trade and Technology: Evidence from Local Labor Markets", Economic Journal, Volume 125, Issue 584, pages 621-646, May 2015.

[12] Autor D., Dorn D., and Hanson, G., and Jae Song, 2014, "Trade Adjustment: Worker Level Evidence", The Quarterly Journal of Economics, vol. 129(4), pages 1799-1860.

[13] Baldwin R., and Lopez-Gonzalez, J., 2015. "Supply-chain Trade: A Portrait of Global Patterns and Several Testable Hypotheses", The World Economy, 38(11), 1682-1721.

[14] Balsvik R., Jensen S., and Salvanes K.G. 2015. "Made in China, Sold in Norway: Local Labor MArket Effects of an Import Shock", Journal of Public Economics, 127, 137-144.

[15] Bas M. and Berthou A., 2013. "Does Input-Trade Liberalization Affects Firms' Foreign Technology Choice?", CEPII Working Paper, No 2013-11.

[16] Bloom N., Draca M., and Van Reenen J., 2016. "Trade-Induced Technical Change: The Impact of Chinese Imports on Innovation, Diffusion and Productivity", Revew of Economic Studies, 83 (1): 87-117. 
[17] Card D., Heining J., and Kline P., 2013. "Workplace Heterogeneity and the Rise of West German Wage Inequality", The Quarterly Journal of Economics, 128(3), 967-1015.

[18] Caselli F., 1999. "Technological Revolutions", American Economic Review, 89(1), 78102.

[19] Davidson C., Matusz, S.J., and Shevchenko, A., 2008. "Globalization and Firm Level Adjustment with Imperfect Labor Markets", Journal of International Economics, 75(2), 295-309.

[20] Davidson C. and Matusz S.J., 2012. "A Model of Globalization and Firm-Worker Matching: How Good is Good Enough?", International Review of Economics \& Finance, 23, 5-15.

[21] Eeckhout J. and Kircher P., 2011. "Identifying Sorting-In Theory", Review of Economic Studies, 78(3), 872-906.

[22] Grossman G. and Rossi-Hansberg E., 2008. "Trading Tasks: A Simple Theory of Offshoring", American Economic Review, 98(5), 19781997.

[23] Hagedorn M., Law T.H., and Manovskii I., 2012. 'Identifying Equilibrium Models of Labor Market Sorting", NBER Working Papers 18661, National Bureau of Economic Research, Inc.

[24] Håkanson C., Lindqvist E., and Vlachos J., 2015. "Sorting by Skill over Time: Evidence from Sweden 1986-2008", Stockholm University, mimeo

[25] Kugler M. and Verhoogen, E., 2011. "Prices, Plant Size, and Product Quality", Review of Economic Studies, 79(1), 307-339.

[26] Lise J., Meghir C., and Robin J.-M., 2013. "Mismatch, Sorting and Wage Dynamics", NBER Working Paper No. 18719.

[27] Low H., Meghir C., and Pistaferri L., 2010. "Wage Risk and Employment Risk over the Life Cycle", American Economic Review, 100(4), 1432-67.

[28] Meghir C. and Pistaferri L., 2004. 'Income Variance Dynamics and Heterogeneity", Econometrica, 72(1), pages 1-32, 01.

[29] Nordström Skans O., Edin P-A. and Holmlund B., 2009. "Wage Dispersion Between and Within Plants: Sweden 1985-2000", NBER Chapters, in: The Structure of Wages: An International Comparison, 217-260.

[30] Schott, P.K., 2004. "Across-Product versus Within-Product Specialization in International Trade", The Quarterly Journal of Economics, 119(2), 647-678.

[31] Stadin K., 2015. "Firms Employment Dynamics and the State of the Labor Market", IFAU Working Paper 2025:20. 


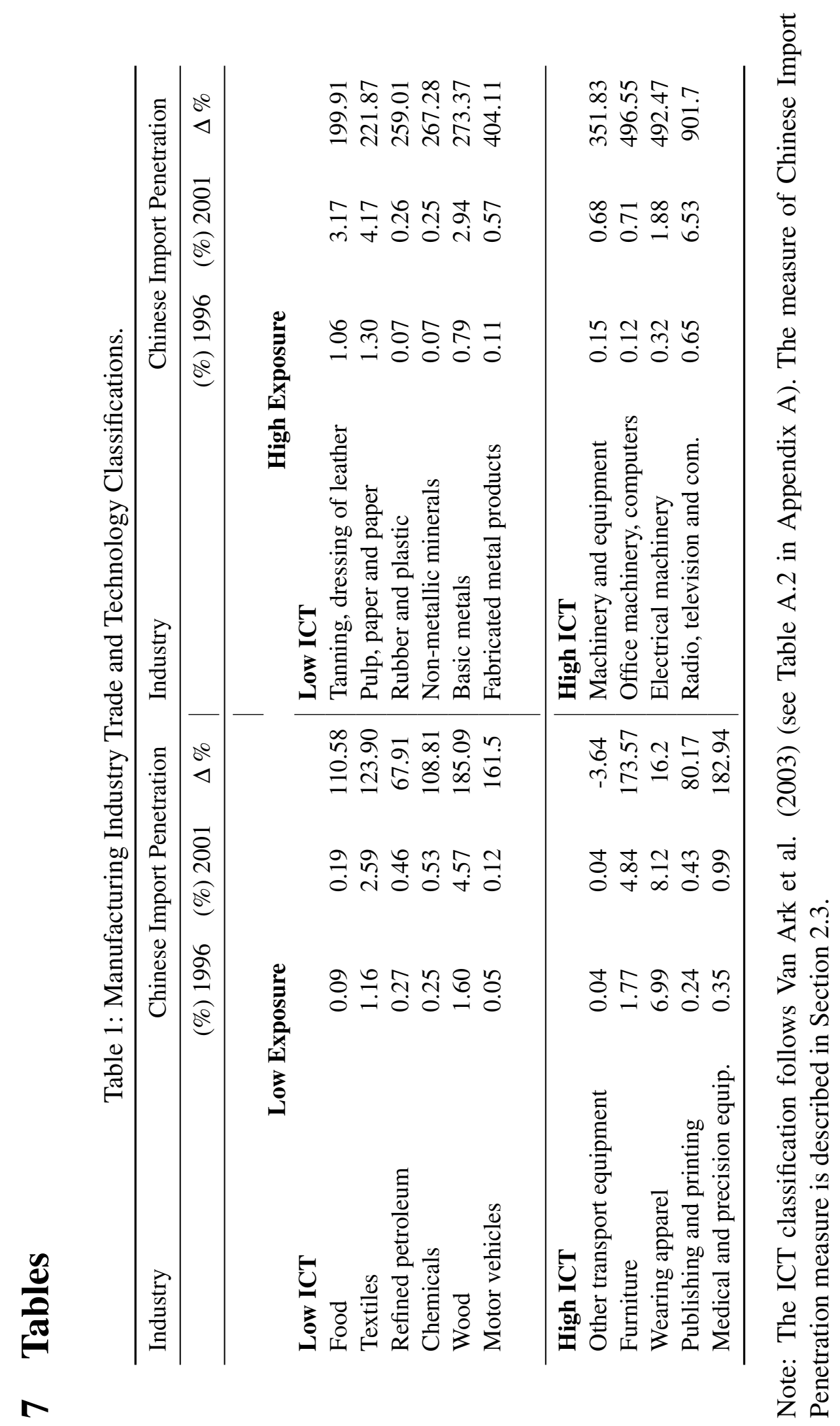


Table 2: Basic Statistics for 1996 and 2006.

\begin{tabular}{|c|c|c|c|c|}
\hline & $\begin{array}{c}(1) \\
\text { Mean }\end{array}$ & $\begin{array}{l}\text { (2) } \\
\text { SD }\end{array}$ & $\begin{array}{c}(3) \\
\text { Mean }\end{array}$ & $\begin{array}{l}(4) \\
\text { SD }\end{array}$ \\
\hline & \multicolumn{2}{|c|}{1996} & \multicolumn{2}{|c|}{2006} \\
\hline & \multicolumn{4}{|c|}{ Panel A: All } \\
\hline Share of males & 0.78 & 0.42 & 0.76 & 0.43 \\
\hline Age & 40.46 & 11.21 & 43.10 & 11.31 \\
\hline Share of workers with some college & 0.19 & 0.39 & 0.26 & 0.44 \\
\hline Share of workers with high school degree & 0.53 & 0.50 & 0.55 & 0.50 \\
\hline Share of workers with incomplete high school & 0.28 & 0.45 & 0.19 & 0.39 \\
\hline \multirow[t]{2}{*}{$\mathrm{N}$} & 453,494 & & 499,914 & \\
\hline & \multicolumn{4}{|c|}{ Panel B: Low ICT } \\
\hline Share of males & 0.79 & 0.41 & 0.77 & 0.42 \\
\hline Age & 40.39 & 11.17 & 42.68 & 11.38 \\
\hline Share of workers with some college & 0.16 & 0.36 & 0.22 & 0.41 \\
\hline Share of workers with high school degree & 0.53 & 0.50 & 0.57 & 0.49 \\
\hline Share of workers with incomplete high school & 0.31 & 0.46 & 0.21 & 0.41 \\
\hline \multirow[t]{2}{*}{$\mathrm{N}$} & 271,169 & & 294,130 & \\
\hline & \multicolumn{4}{|c|}{ Panel C: High ICT } \\
\hline Share of males & 0.76 & 0.43 & 0.75 & 0.43 \\
\hline Age & 40.57 & 11.26 & 43.70 & 11.17 \\
\hline Share of workers with some college & 0.24 & 0.43 & 0.32 & 0.47 \\
\hline Share of workers with high school degree & 0.52 & 0.50 & 0.52 & 0.50 \\
\hline Share of workers with incomplete high school & 0.23 & 0.42 & 0.16 & 0.37 \\
\hline $\mathrm{N}$ & 182,325 & & 205,784 & \\
\hline
\end{tabular}

Note: The table presents the mean and standard deviation (SD) for the demographic characteristics of the individuals used in our analysis. 


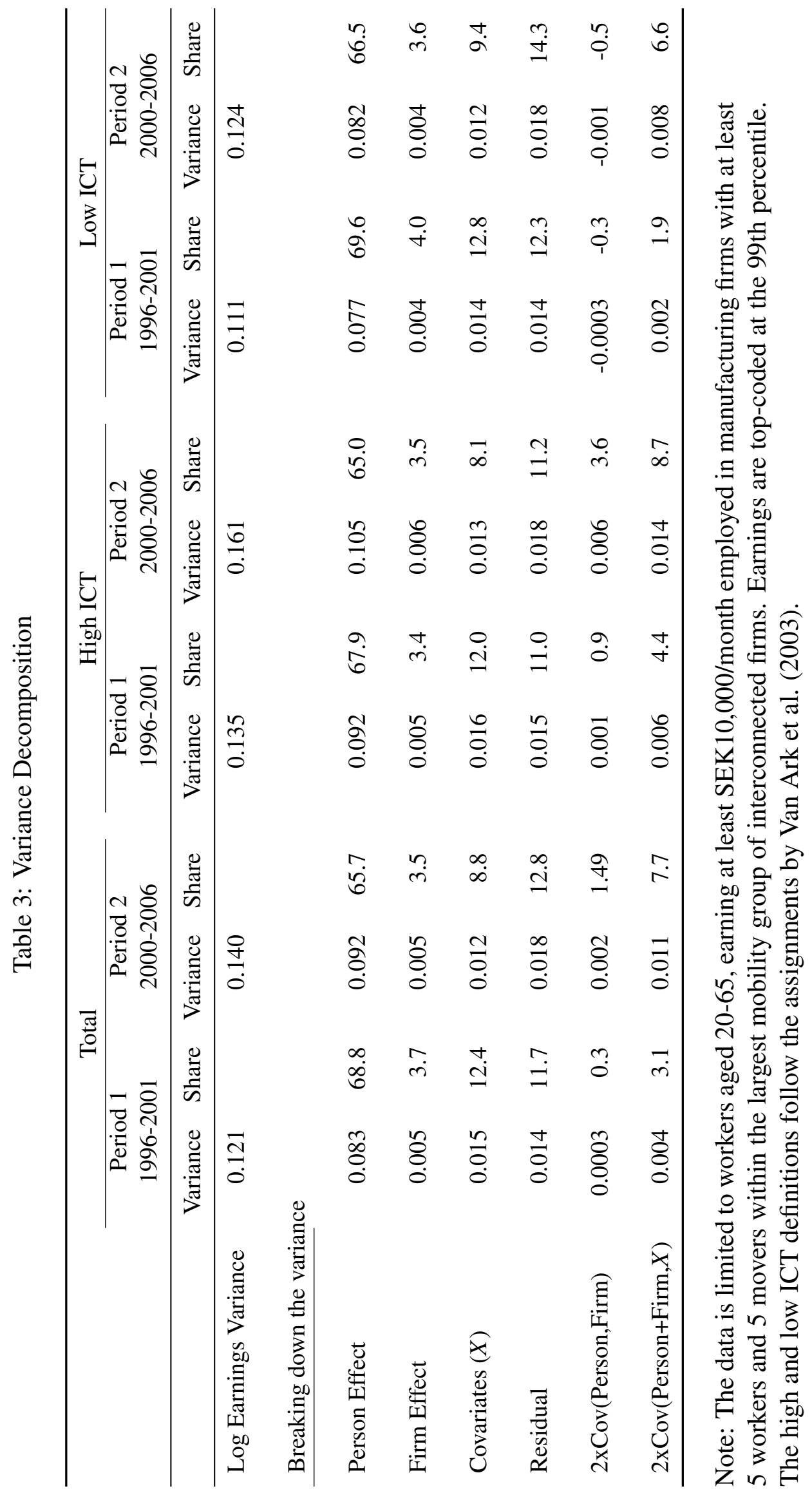


Table 4: Transition of Workers between Period 1 and Period 2 by Industry Type (row percentages, as a share of P1).

\begin{tabular}{|c|c|c|c|c|c|c|c|c|c|c|}
\hline & (1) & (2) & (3) & (4) & (5) & (6) & (7) & (8) & (9) & $(10)$ \\
\hline & \multicolumn{10}{|c|}{ Period 2} \\
\hline \multirow[b]{3}{*}{ Firm Type } & \multicolumn{4}{|c|}{ Low ICT } & \multicolumn{4}{|c|}{ High ICT } & \multirow{3}{*}{ Switch } & \multirow{3}{*}{ Exit } \\
\hline & \multicolumn{2}{|c|}{ Low China } & \multicolumn{2}{|c|}{ High China } & \multicolumn{2}{|c|}{ Low China } & \multicolumn{2}{|c|}{ High China } & & \\
\hline & Low & High & Low & High & Low & High & Low & High & & \\
\hline \multicolumn{11}{|c|}{ Period 1} \\
\hline \multicolumn{11}{|c|}{ Panel A: Low ICT-Low China } \\
\hline LFLP & 31.8 & 16.3 & 1.1 & 1.2 & 1.1 & 0.5 & 0.4 & 0.7 & 18.4 & 28.5 \\
\hline LFHP & 39.3 & 17.7 & 1.2 & 1.0 & 0.5 & 0.4 & 0.2 & 1.0 & 19.3 & 19.6 \\
\hline HFLP & 4.4 & 56.4 & 0.5 & 1.1 & 0.3 & 0.6 & 0.3 & 1.0 & 14.6 & 20.7 \\
\hline HFHP & 2.9 & 71.0 & 0.3 & 0.9 & 0.1 & 0.5 & 0.2 & 1.1 & 12.9 & 10.1 \\
\hline \multicolumn{11}{|c|}{ Panel B: Low ICT-High China } \\
\hline LFLP & 0.7 & 0.7 & 23.0 & 8.4 & 36.0 & 0.2 & 0.6 & 0.6 & 8.2 & 21.6 \\
\hline LFHP & 1.0 & 1.0 & 39.6 & 14.8 & 7.1 & 0.2 & 1.4 & 1.2 & 12.2 & 21.4 \\
\hline HFLP & 0.6 & 1.5 & 8.0 & 50.8 & 0.4 & 0.4 & 0.5 & 1.3 & 12.6 & 23.7 \\
\hline HFHP & 0.3 & 1.2 & 11.5 & 64.1 & 0.1 & 0.4 & 0.3 & 1.3 & 7.7 & 13.0 \\
\hline \multicolumn{11}{|c|}{ Panel C: High ICT-Low China } \\
\hline LFLP & 0.5 & 0.6 & 0.5 & 0.5 & 45.9 & 9.8 & 0.2 & 0.4 & 13.5 & 28.1 \\
\hline LFHP & 0.3 & 0.5 & 0.6 & 0.4 & 44.2 & 13.2 & 0.4 & 0.5 & 15.7 & 24.1 \\
\hline HFLP & 0.3 & 1.1 & 0.4 & 0.8 & 6.0 & 49.4 & 0.3 & 3.1 & 16.1 & 22.3 \\
\hline HFHP & 0.1 & 1.0 & 0.3 & 0.5 & 6.4 & 58.6 & 0.4 & 7.1 & 13.2 & 12.4 \\
\hline \multicolumn{11}{|c|}{ Panel D: High ICT-High China } \\
\hline LFLP & 0.4 & 0.7 & 1.4 & 1.5 & 25.3 & 0.5 & 24.8 & 14.3 & 10.2 & 20.9 \\
\hline LFHP & 0.3 & 0.7 & 1.6 & 1.4 & 3.3 & 1.3 & 28.5 & 26.4 & 17.4 & 19.1 \\
\hline HFLP & 0.3 & 1.4 & 0.6 & 1.6 & 0.4 & 3.9 & 4.8 & 56.3 & 12.9 & 17.7 \\
\hline HFHP & 0.2 & 1.4 & 0.4 & 1.4 & 0.2 & 5.9 & 3.0 & 68.2 & 11.1 & 8.2 \\
\hline Stayers Total & 4.4 & 23.9 & 6.7 & 16.0 & 9.6 & 12.9 & 3.5 & 23.0 & & \\
\hline Newcomers & 6.6 & 19.6 & 8.3 & 15.8 & 5.2 & 12.0 & 5.2 & 27.4 & & \\
\hline TOTAL & 3.5 & 17.2 & 5.1 & 11.8 & 6.6 & 9.4 & 2.8 & 17.6 & 11.1 & 14.9 \\
\hline
\end{tabular}

Note: See Table 1 for the industries classified as "Low/High China" and "Low/High ICT". We divide individuals into four possible groups (LFLP, LFHP, HFLP, HFHP) in Panels A-D, where the two first letters denote the firm type and the two last denote the person type. "LF (HF)" is a firm with fixed effects in bins 1-4 (7-10) of Figure 1 in Period 1. "LP (HP)" is a person with fixed effects in bins 1-4 (7-10) of Figure 1 in Period 1. Individuals in column "Switch" are employed in a manufacturing job in Period 1, but switched to a non-manufacturing job in Period 2. Individuals in column "Exit" leave the sample for whole Period 2, which can be due to an income below the income restriction of $120,000 \mathrm{SEK} /$ year, become older than 65 , leave to unemployment, leave labor force, retire or die. "Stayers" are individuals present in Periods 1 and 2. "Newcomers" are individuals out of our sample in Period 1 (either because they did not meet the income restriction, were younger than 20 years old, were out of the labor force, unemployed or working outside the manufacturing sector), but who enter the manufacturing sector in Period 2. 


\section{Figures}

Figure 1: Distributions of worker and firm fixed effects.

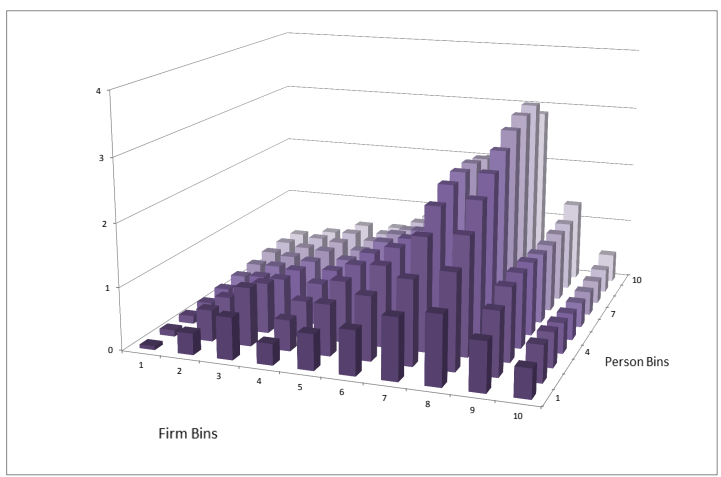

(a) Period 1: 1996-2001

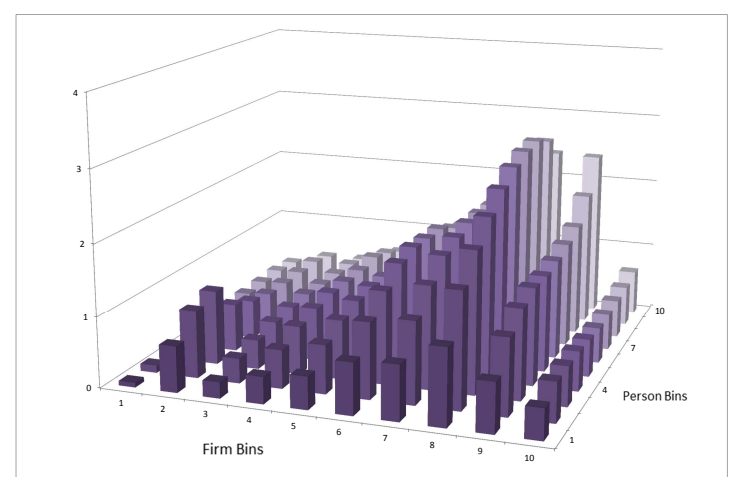

(b) Period 2: 2001-2006

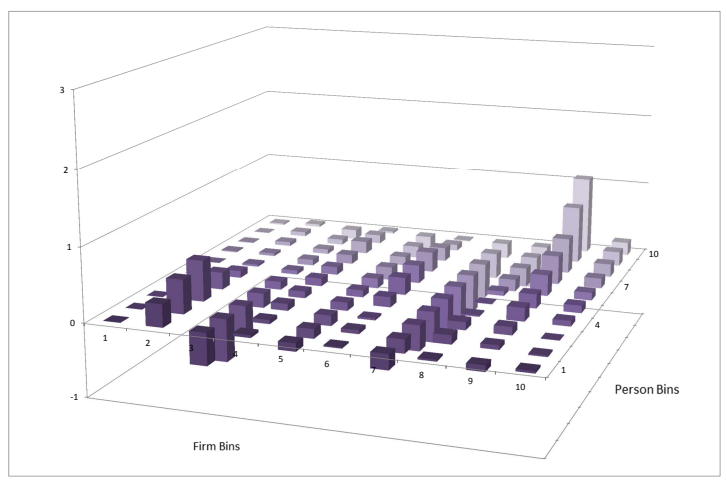

(c) P1 to P2 difference

Note: Graphs (a) and (b) present the joint distribution of worker and firm fixed effects resulting from estimating model (2). The worker and firm fixed effects are ranked by deciles across the distribution of all workers. Graph (c) plots the difference for each decile of fixed effects between Periods 1 and 2. 


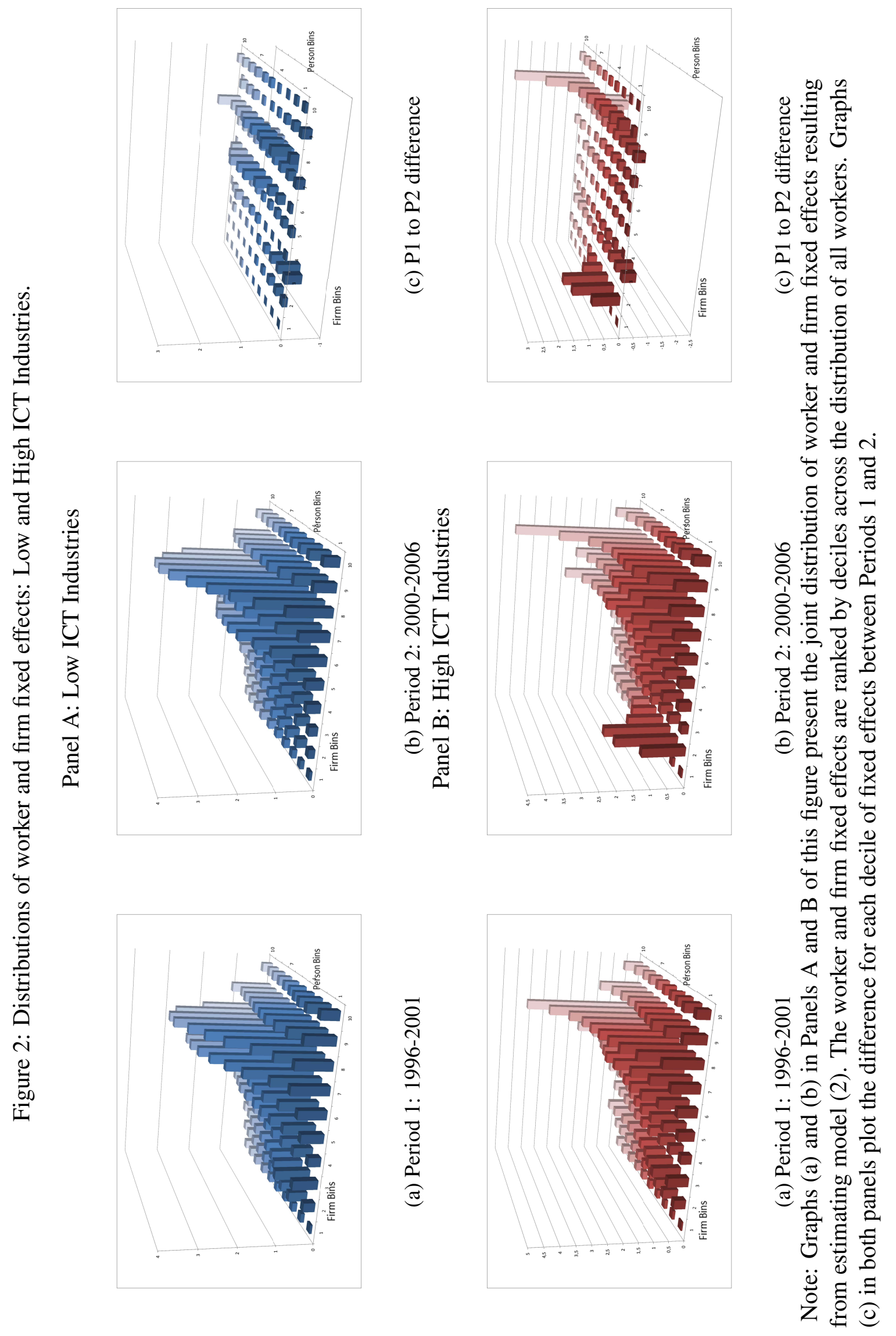




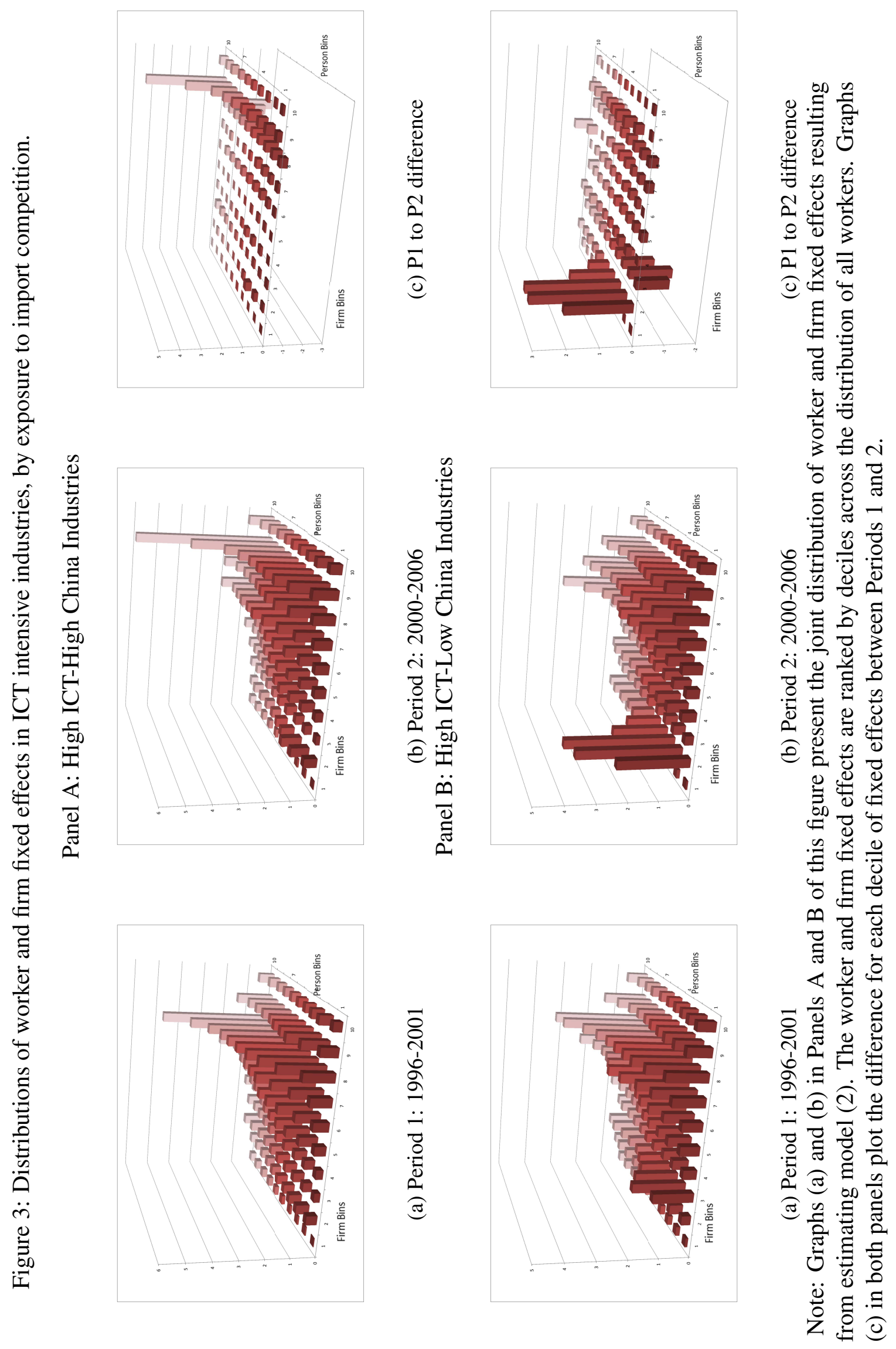


Figure 4: The effect of an increase in imports from China on the steady-state variables: two ICT intensive industries ( $N$ and $T$ ) of which only $T$ industry is exposed to an increase in Chinese import penetration, represented by a decrease in the productivity of unqualified jobs, $y_{T}^{1}$.
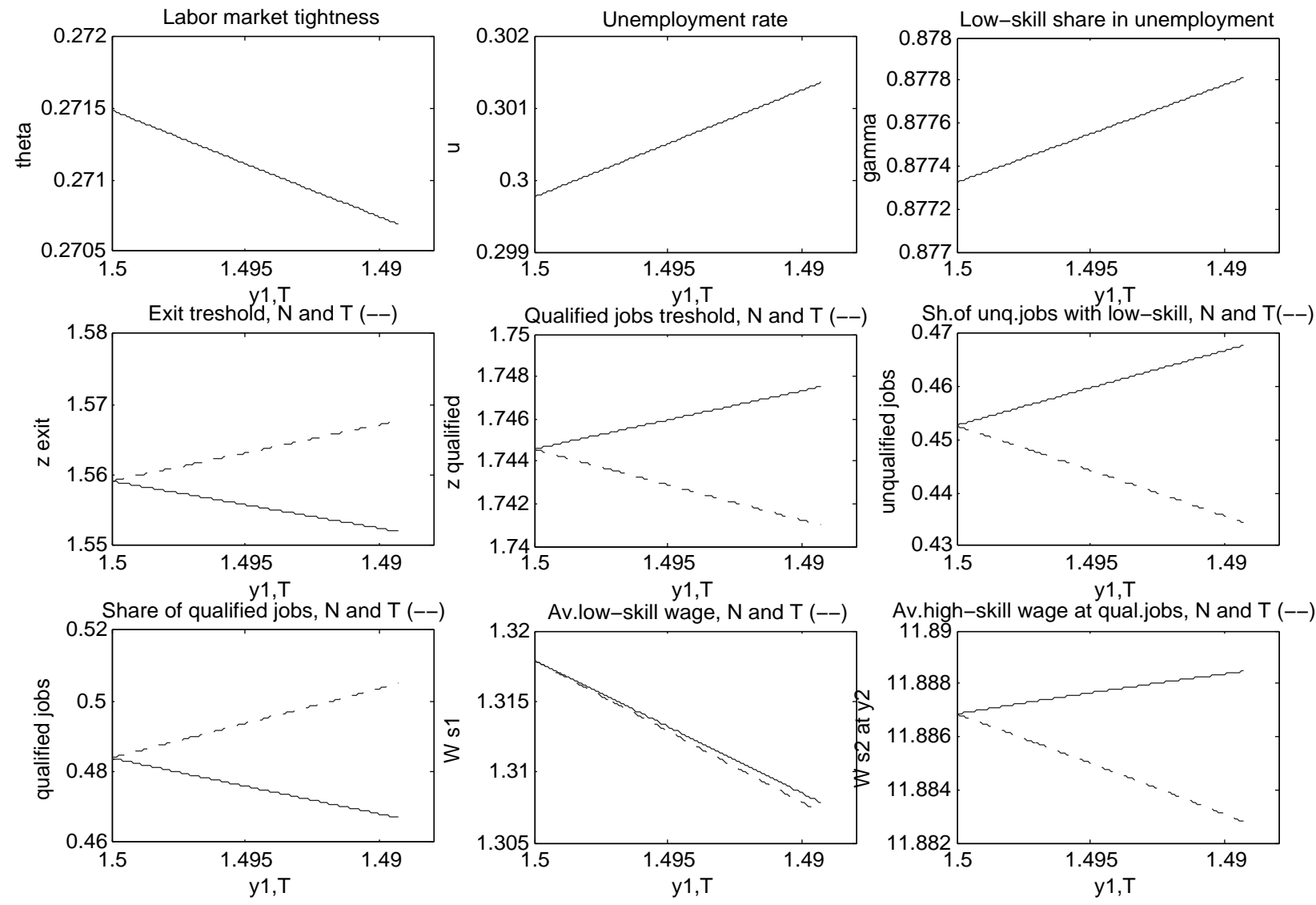
Trade Competition, Technology and Labour Re-Allocation

\author{
Selva Baziki \\ Rita Ginja
}

Teodora Borota Milicevic

ONLINE APPENDIX

NOT FOR PUBLICATION 


\section{A Tables}

Table A.1: Description of Variables in Data.

\begin{tabular}{|c|c|}
\hline Firm Data & \\
\hline Total Wages & Sum of personnel costs for the year \\
\hline Total Sales & Sum of revenues for the year \\
\hline Profit & Reported profit for the year \\
\hline Total Exports & Reported exports for the year (2000-2006) \\
\hline Firm age & Calculated from years active in the data set \\
\hline Capital (K) & $\begin{array}{l}\text { Sum of the following reported tangible assets for the year: } \\
\text { Land and Buildings } \\
\text { Machinery and Equipment } \\
\text { Ongoing Construction and advance payments for tangible fixed assets }\end{array}$ \\
\hline Total Employees (N) & Total employees \\
\hline Capital Intensity & Calculated as $\mathrm{K} / \mathrm{N}$ \\
\hline Industry Classification & $\begin{array}{l}\text { Industry Codes are reported in two different systems }(1992,2002) \text { which } \\
\text { all have been converted to SNI2002 at the 2-digit and 3-digit level }\end{array}$ \\
\hline \multicolumn{2}{|l|}{ Business Register } \\
\hline Legal Form & Classification by type of legal entity \\
\hline Controlling Ownership & Standard Classification by ownership control \\
\hline \multicolumn{2}{|l|}{ Employee Data } \\
\hline Annual Wage & Taxed wage income \\
\hline Age & As reported \\
\hline Gender & As reported \\
\hline Level of Highest Education & $\begin{array}{l}\text { The following categories: } \\
\text { Pre High School } \\
\text { Some High School without a diploma } \\
\text { High School diploma } \\
2 \text { or less years of University } \\
\text { More than } 2 \text { years of University (includes those with diploma) } \\
\text { Postgraduate Studies }\end{array}$ \\
\hline Targeted Field of Education & Targeted diploma subject \\
\hline
\end{tabular}

Notes: The source of Firm Data is the Account Statistics (FEK).

Business Register data comes from the Business Register Database (Fretagsregistret). Data available from 1980 onwards.

The source of Employee Data is the Register Based Labour Statistics (RAMS). Each individual is linked to a firm, and a plant where applicable. 
Table A.2: Information and Communication Technology Classifications.

\begin{tabular}{ll}
\hline Van Ark et al. (2003) Classifications & Our own ICT Classifications \\
\hline & \\
ICT Producing Industries & High ICT Industries \\
30- Office machinery, computers & 18-Wearing apparel \\
313-Insulated Wire & 22-Publishing and printing \\
32-Radio, TV and comunic. equip. & 29-Machinery and Equipment \\
331-3-Medical and precision equip. & 30- Office machinery, computers \\
& 31-Electrical machinery \\
ICT-using Industries & 32-Radio, TV and comunic. equip. \\
18-Wearing apparel & 33-Medical and precision equip. \\
22-Publishing and printing & 35-Other transport equipment \\
29-Machinery and Equipment & 36-Furniture \\
31(ex313)-Electrical machinery & \\
334-5-Other Instruments & \\
35-Other transport equipment & \\
36-Furniture & \\
37-Recycling &
\end{tabular}

\begin{tabular}{ll} 
Non-ICT Industries & Low ICT Industries \\
15-Food & 15-Food \\
16-Tobacco & 16-Tobacco \\
17-Textiles & 17-Textiles \\
19-Tanning, dressing of leather & 19-Tanning, dressing of leather \\
20-Wood & 20-Wood \\
21-Pulp, paper and paper products & 21-Pulp, paper and paper products \\
23-Refined petroleum & 23-Refined petroleum \\
24-Chemicals & 24-Chemicals \\
25-Rubber and plastic products & 25-Rubber and plastic products \\
26-Other non-metallic minerals & 26-Other non-metallic minerals \\
27-Basic metals & 27-Basic metals \\
28-Fabricated metal products & 28-Fabricated metal products \\
34-Motor vehicles and trailers & 34-Motor vehicles and trailers \\
& \\
\hline
\end{tabular}

Notes: This table presents the classification of industries according to their ICT intensity. The column on the left includes the three categories presented in the classification from van Ark et al. (2003). The column on the right presents our grouping of Swedish Industries. Our category of low-ICT industries includes the Non-ICT industries in van Ark et al. (2003) and we group into High-ICT industries ICT-producing and ICT-using industries. 
Table A.3: Matching UN Comtrade SITC Codes to Swedish Industries (SNI)

\begin{tabular}{|c|c|c|c|}
\hline SITC & SITC Name & SNI & SNI Name \\
\hline 1 & Meat and meat preparations & \multirow[t]{6}{*}{15} & \multirow[t]{6}{*}{ Manufacture of food products and beverages } \\
\hline 4 & Cereals and cereal preparations & & \\
\hline 6 & Sugars, Sugar preparations and honey & & \\
\hline 7 & Coffee, tea, cocoa, spices, and manufactures thereof & & \\
\hline 9 & Miscellaneous edible products and preparations & & \\
\hline 11 & Beverages & & \\
\hline 12 & Tobacco and tobacco manufactures & 16 & Manufacture of tobacco products \\
\hline 65 & $\begin{array}{l}\text { Textile yarn, fabrics, made-up articles, n.e.s., and related } \\
\text { products }\end{array}$ & 17 & Manufacture of textiles \\
\hline $\begin{array}{l}84 \\
85\end{array}$ & $\begin{array}{l}\text { Articles of apparel and clothing accessories } \\
\text { Footwear }\end{array}$ & 18 & Manufacture of wearing apparel; dressing and dyeing of fur \\
\hline 61 & Leather, leather manufactures & 19 & $\begin{array}{l}\text { Tanning and dressing of leather; manufacture of luggage, } \\
\text { handbags, saddlery, harness and footwear }\end{array}$ \\
\hline 63 & Cork and wood manufactures (excluding furniture) & 20 & $\begin{array}{l}\text { Manufacture of wood and of products of wood and cork, } \\
\text { except furniture; manufacture of articles of straw and plait- } \\
\text { ing materials }\end{array}$ \\
\hline 64 & $\begin{array}{l}\text { Paper, paperboard and articles of paper pulp, of paper or } \\
\text { of paperboard }\end{array}$ & 21 & Manufacture of pulp, paper and paper products \\
\hline 892 & Printed matter & 22 & Publishing, printing and reproduction of recorded media \\
\hline 898 & $\begin{array}{l}\text { Musical instruments and parts and accessories thereof; } \\
\text { records, tapes and other sound or similar recordings }\end{array}$ & & \\
\hline 325 & $\begin{array}{l}\text { Coke and semi-coke (including char) of coal, of lignite or } \\
\text { of peat, whether or not agglomerated; retort carbon }\end{array}$ & 23 & $\begin{array}{l}\text { Manufacture of coke, refined petroleum products and nu- } \\
\text { clear fuel }\end{array}$ \\
\hline 33 & Petroleum, petroleum products and related materials & & \\
\hline $\begin{array}{l}5 \text { excl } \\
57 \& 58\end{array}$ & Chemicals and related products, n.e.s. & 24 & Manufacture of chemicals and chemical products \\
\hline 62 & Rubber manufactures, n.e.s. & 25 & Manufacture of rubber and plastic products \\
\hline 57 & Plastics in primary forms & & \\
\hline 58 & Plastics in non-primary forms & & \\
\hline 66 & Non-metallic mineral manufactures, n.e.s. & 26 & Manufacture of other non-metallic mineral products \\
\hline 67 & Iron and steel & 27 & Manufacture of basic metals \\
\hline 68 & Non-ferrous metals & & \\
\hline 69 & Manufactures of metals, n.e.s. & 28 & $\begin{array}{l}\text { Manufacture of fabricated metal products, except machin- } \\
\text { ery and equipment }\end{array}$ \\
\hline 74 & $\begin{array}{l}\text { General industrial machinery and equipment, n.e.s., and } \\
\text { machine parts, n.e.s. }\end{array}$ & 29 & Manufacture of machinery and equipment n.e.c. \\
\hline 75 & Office machines and automatic data-processing machines & 30 & Manufacture of office machinery and computers \\
\hline 77 & $\begin{array}{l}\text { Electrical machinery, apparatus and appliances, n.e.s., and } \\
\text { electrical parts thereof }\end{array}$ & 31 & Manufacture of electrical machinery and apparatus n.e.c. \\
\hline 76 & $\begin{array}{l}\text { Telecommunications and sound-recording and reproduc- } \\
\text { ing apparatus and equipment }\end{array}$ & 32 & $\begin{array}{l}\text { Manufacture of radio, television and communication } \\
\text { equipment and apparatus }\end{array}$ \\
\hline 88 & $\begin{array}{l}\text { Photographic apparatus, equipment and supplies and opti- } \\
\text { cal goods, n.e.s.; watches and clocks }\end{array}$ & 33 & $\begin{array}{l}\text { Manufacture of medical, precision and optical instruments, } \\
\text { watches and clocks }\end{array}$ \\
\hline 872 & $\begin{array}{l}\text { Instruments and appliances, n.e.s., for medical, surgical, } \\
\text { dental or veterinary purposes }\end{array}$ & & \\
\hline 78 & Road vehicles (including air-cushion vehicles) & 34 & Manufacture of motor vehicles, trailers and semi-trailers \\
\hline 79 & Other transport equipment & 35 & Manufacture of other transport equipment \\
\hline 82 & $\begin{array}{l}\text { Furniture, and parts thereof; bedding, mattresses, mattress } \\
\text { supports, cushions and similar stuffed furnishings }\end{array}$ & 36 & Manufacture of furniture; manufacturing n.e.c. \\
\hline- & - & 37 & Recycling \\
\hline
\end{tabular}

Notes: This table presents our matching between the list of products available in the UN Comtrade data base (SITC) and the Swedish industries (SNI). From the product level information available from UN Comtrade it is not possible to identify a matching product to the recycling industry. 
Table A.4: Number of workers and firms in the manufacturing sector and in the largest mobility group: for the period of 1996-2006 and by subperiod (1996-2001 and 2000-2006).

\begin{tabular}{|c|c|c|c|c|c|c|}
\hline \multirow[b]{3}{*}{ Total Period: 1996-2006 } & \multicolumn{3}{|c|}{ Total Population } & \multicolumn{3}{|c|}{ Largest Mobility Group - Firms } \\
\hline & $\begin{array}{l}\text { No of } \\
\text { Firms }\end{array}$ & $\begin{array}{c}\text { No of } \\
\text { Workers }\end{array}$ & $\begin{array}{l}\text { Log Real } \\
\text { Earnings }\end{array}$ & $\begin{array}{l}\text { No of } \\
\text { Firms }\end{array}$ & $\begin{array}{c}\text { No of } \\
\text { Workers }\end{array}$ & $\begin{array}{l}\text { Log Real } \\
\text { Earnings }\end{array}$ \\
\hline & 12653 & 1064274 & $\begin{array}{l}10.36 \\
(0.36)\end{array}$ & 12181 & 1059438 & $\begin{array}{l}10.36 \\
(0.36)\end{array}$ \\
\hline Percent of Mobility Group vs Total (\%) & & & & $96.3 \%$ & $99.5 \%$ & \\
\hline Period 1: 1996-2001 & 10596 & 866743 & $\begin{array}{l}10.31 \\
(0.35)\end{array}$ & 9632 & 856043 & $\begin{array}{l}10.31 \\
(0.35)\end{array}$ \\
\hline Percent of Mobility Group vs Total (\%) & & & & $90.9 \%$ & $98.8 \%$ & \\
\hline Period 2: 2000-2006 & 10363 & 889919 & $\begin{array}{l}10.40 \\
(0.37)\end{array}$ & 9596 & 881109 & $\begin{array}{l}10.40 \\
(0.37)\end{array}$ \\
\hline Percent of Mobility Group vs Total (\%) & & & & $92.6 \%$ & $99.0 \%$ & \\
\hline
\end{tabular}

Note: Standard deviation of log earnings in parentheses. 
Table A.5: Characteristics of Industries (2006 vs. 1996).

\begin{tabular}{lcc|cc|cc|cc}
\hline & \multicolumn{2}{c}{ Share of } & \multicolumn{2}{c}{ Share of } & \multicolumn{2}{c}{ Average firm } & \multicolumn{2}{c}{ Number of } \\
& \multicolumn{2}{c}{ Employment } & \multicolumn{2}{c}{ College } & \multicolumn{2}{c}{ size } & \multicolumn{2}{c}{ Firms } \\
Classification & 1996 & 2006 & 1996 & 2006 & 1996 & 2006 & 1996 & 2006 \\
\hline & & & & & & & & \\
Panel A: Low China-Low ICT & & & & & & & & \\
Food & $7 \%$ & $7 \%$ & $11 \%$ & $16 \%$ & 681 & 839 & 599 & 597 \\
Textiles & $1 \%$ & $1 \%$ & $12 \%$ & $17 \%$ & 152 & 179 & 151 & 102 \\
Refined petroleum & $1 \%$ & $0 \%$ & $38 \%$ & $45 \%$ & 672 & 446 & 9 & 10 \\
Chemicals & $5 \%$ & $7 \%$ & $33 \%$ & $47 \%$ & 1418 & 4158 & 199 & 202 \\
Wood & $5 \%$ & $5 \%$ & $8 \%$ & $11 \%$ & 342 & 322 & 698 & 598 \\
Motor vehicles and trailers & $13 \%$ & $13 \%$ & $21 \%$ & $27 \%$ & 6667 & 7120 & 227 & 244 \\
Sector Mean & $4 \%$ & $4 \%$ & $21 \%$ & $27 \%$ & 653 & 1189 & 331 & 302 \\
& & & & & & & & \\
Panel B: Low China-High ICT & & & & & & & & \\
Other transport equipment & $3 \%$ & $4 \%$ & $26 \%$ & $37 \%$ & 1742 & 3257 & 115 & 116 \\
Furniture & $3 \%$ & $5 \%$ & $9 \%$ & $10 \%$ & 110 & 7995 & 400 & 360 \\
Wearing apparel & $<0.5 \%$ & $<0.5 \%$ & $8 \%$ & $20 \%$ & 71 & 88 & 54 & 31 \\
Publishing and printing & $6 \%$ & $5 \%$ & $24 \%$ & $34 \%$ & 209 & 174 & 876 & 645 \\
Medical and precision equip. & $3 \%$ & $3 \%$ & $39 \%$ & $44 \%$ & 1232 & 331 & 249 & 250 \\
Sector Mean & $3 \%$ & $4 \%$ & $17 \%$ & $25 \%$ & 533 & 2879 & 361 & 288 \\
& & & & & & & & \\
Panel C: High China-Low ICT & & & & & & & & \\
Tanning, dressing of leather & $<0.5 \%$ & $<0.5 \%$ & $5 \%$ & $12 \%$ & 94 & 158 & 33 & 22 \\
Pulp, paper and paper products & $7 \%$ & $6 \%$ & $15 \%$ & $20 \%$ & 1094 & 730 & 157 & 156 \\
Rubber and plastic products & $3 \%$ & $3 \%$ & $15 \%$ & $16 \%$ & 369 & 156 & 393 & 385 \\
Other non-metallic minerals & $3 \%$ & $2 \%$ & $12 \%$ & $16 \%$ & 375 & 336 & 199 & 168 \\
Basic metals & $6 \%$ & $5 \%$ & $12 \%$ & $17 \%$ & 2257 & 1345 & 134 & 151 \\
Fabricated metal products & $9 \%$ & $9 \%$ & $10 \%$ & $13 \%$ & 113 & 139 & 1732 & 1733 \\
Sector Mean & $4 \%$ & $3 \%$ & $12 \%$ & $16 \%$ & 838 & 545 & 183 & 176 \\
& & & & & & & & \\
Panel D: High China-High ICT & & & & & & & & \\
Machinery and equipment & $16 \%$ & $15 \%$ & $20 \%$ & $27 \%$ & 621 & 778 & 1144 & 991 \\
Office machinery, computers & $1 \%$ & $1 \%$ & $48 \%$ & $35 \%$ & 225 & 229 & 51 & 39 \\
Electrical machinery & $4 \%$ & $4 \%$ & $24 \%$ & $32 \%$ & 709 & 1993 & 302 & 265 \\
Radio, television and com. & $4 \%$ & $4 \%$ & $40 \%$ & $65 \%$ & 4995 & 12229 & 122 & 93 \\
Sector Mean & $6 \%$ & $6 \%$ & $26 \%$ & $27 \%$ & 598 & 886 & 420 & 368 \\
\hline & & & & & & & & \\
\hline
\end{tabular}

Note: The table includes some basic characteristics for each industry in the manufacturing sector, grouped according to the definitions of ICT intensity and exposure to import competition for the first and last years in our sample: 1996 and 2006. There are four characteristics for each industry: share of employment in the industry relative to overall manufacturing sector, share of workers in industry that attended some college, average number of workers per firm and number of firm operating in each industry. 
Table A.6: Multinomial logit estimates for the probability of being in one of the four quadrants: Low Firm-Low Person (LFLP), High Person-Low Firm (HPLF), Low Person-High Firm (LPHF), and High Person-High Firm (HPHF); Marginal Effects.

\begin{tabular}{|c|c|c|c|c|}
\hline & $\begin{array}{c}(1) \\
\text { LPLF }\end{array}$ & $\begin{array}{c}(2) \\
\text { HPLF }\end{array}$ & $\begin{array}{c}(3) \\
\text { LPHF }\end{array}$ & $\begin{array}{c}(4) \\
\text { HPHF }\end{array}$ \\
\hline Low-China $\times$ Low-ICT & $\begin{array}{c}0.032 * * * \\
(0.001)\end{array}$ & $\begin{array}{c}0.019 * * * \\
(0.001)\end{array}$ & $\begin{array}{c}-0.029 * * * \\
(0.002)\end{array}$ & $\begin{array}{c}-0.022 * * * \\
(0.002)\end{array}$ \\
\hline Low-China $\times$ High-ICT & $\begin{array}{c}0.027 * * * \\
(0.002)\end{array}$ & $\begin{array}{c}0.047 * * * \\
(0.001)\end{array}$ & $\begin{array}{c}-0.035 * * * \\
(0.002)\end{array}$ & $\begin{array}{c}-0.039 * * * \\
(0.002)\end{array}$ \\
\hline High-China $\times$ Low-ICT & $\begin{array}{c}0.0178 * * * \\
(0.001)\end{array}$ & $\begin{array}{c}0.017 * * * \\
(0.001)\end{array}$ & $\begin{array}{c}-0.011 * * * \\
(0.002)\end{array}$ & $\begin{array}{c}-0.023 * * * \\
(0.002)\end{array}$ \\
\hline Low-China $\times$ Low-ICT $\times$ Period 2 & $\begin{array}{c}-0.035^{* * *} * \\
(0.002)\end{array}$ & $\begin{array}{c}-0.018 * * * \\
(0.002)\end{array}$ & $\begin{array}{c}0.059 * * * \\
(0.003)\end{array}$ & $\begin{array}{c}-0.006 * * \\
(0.003)\end{array}$ \\
\hline Low-China $\times$ High-ICT $\times$ Period 2 & $\begin{array}{c}0.047 * * * \\
(0.002)\end{array}$ & $\begin{array}{c}-0.025^{* * *} * \\
(0.002)\end{array}$ & $\begin{array}{c}-0.014 * * * \\
(0.003)\end{array}$ & $\begin{array}{c}-0.009 * * * \\
(0.003)\end{array}$ \\
\hline High-China $\times$ Low-ICT $\times$ Period 2 & $\begin{array}{c}-0.010 * * * \\
(0.002)\end{array}$ & $\begin{array}{c}0.016 * * * \\
(0.002)\end{array}$ & $\begin{array}{c}0.007 * * \\
(0.003)\end{array}$ & $\begin{array}{c}-0.014 * * * \\
(0.003)\end{array}$ \\
\hline Observations & 880,491 & & & \\
\hline
\end{tabular}

Note: Regressions also control for: year dummies, the gender of the individual, highest education, age, tenure in firm and firm characteristics (capital per worker, profit per worker, share of high school and college graduates). Period 2 workers are restricted to those who were present in Period 1. The coefficients in the table are marginal effects. Reference interaction group is High ChinaHigh ICT in Period 1. *** $\mathrm{p}<0.01, * * \mathrm{p}<0.05, * \mathrm{p}<0.10$. 
Table A.7: Industry Type Breakdown of Firms and Workers between Period 1 and Period 2 (Person count).

\begin{tabular}{|c|c|c|c|c|c|c|c|c|c|c|c|}
\hline \multirow[b]{4}{*}{ Firm Type } & \multicolumn{11}{|c|}{ Period 2} \\
\hline & \multicolumn{4}{|c|}{ Low ICT } & \multicolumn{4}{|c|}{ High ICT } & \multirow{3}{*}{ Switch } & \multirow{3}{*}{ Exit } & \multirow{3}{*}{ Sum } \\
\hline & \multicolumn{2}{|c|}{ Low China } & \multicolumn{2}{|c|}{ High China } & \multicolumn{2}{|c|}{ Low China } & \multicolumn{2}{|c|}{ High China } & & & \\
\hline & Low & High & Low & High & Low & High & Low & High & & & \\
\hline \multicolumn{12}{|c|}{ Period 1} \\
\hline LFLP & 3630 & 1865 & 124 & 134 & 123 & 54 & 48 & 82 & 2106 & 3249 & 11415 \\
\hline LFHP & 3784 & 1698 & 112 & 94 & 44 & 35 & 24 & 92 & 1852 & 1882 & 9617 \\
\hline HFLP & 1712 & 21701 & 190 & 441 & 112 & 218 & 104 & 392 & 5623 & 7980 & 38473 \\
\hline HFHP & 1419 & 34544 & 140 & 425 & 47 & 259 & 112 & 545 & 6255 & 4909 & 48655 \\
\hline \multicolumn{12}{|c|}{ Panel B: Low ICT-High China } \\
\hline LFLP & 163 & 152 & 5181 & 1886 & 8126 & 55 & 125 & 145 & 1838 & 4877 & 22548 \\
\hline LFHP & 114 & 122 & 4657 & 1736 & 838 & 28 & 169 & 141 & 1438 & 2513 & 11756 \\
\hline HFLP & 172 & 440 & 2315 & 14643 & 127 & 106 & 143 & 384 & 3645 & 6840 & 28815 \\
\hline HFHP & 93 & 406 & 3757 & 20874 & 46 & 132 & 103 & 408 & 2522 & 4248 & 32589 \\
\hline \multicolumn{12}{|c|}{ Panel C: High ICT-Low China } \\
\hline LFLP & 57 & 73 & 61 & 57 & 5779 & 1238 & 30 & 55 & 1695 & 3541 & 12586 \\
\hline LFHP & 27 & 46 & 51 & 32 & 3880 & 1160 & 37 & 47 & 1378 & 2112 & 8770 \\
\hline HFLP & 66 & 241 & 96 & 177 & 1292 & 10697 & 72 & 679 & 3490 & 4827 & 21637 \\
\hline HFHP & 36 & 273 & 86 & 136 & 1700 & 15602 & 94 & 1901 & 3507 & 3309 & 26644 \\
\hline \multicolumn{12}{|c|}{ Panel D: High ICT-High China } \\
\hline LFLP & 40 & 77 & 147 & 161 & 2665 & 53 & 2621 & 1506 & 1077 & 2203 & 10550 \\
\hline LFHP & 26 & 61 & 137 & 119 & 280 & 111 & 2418 & 2236 & 1470 & 1614 & 8472 \\
\hline HFLP & 114 & 472 & 214 & 532 & 132 & 1281 & 1576 & 18638 & 4285 & 5864 & 33108 \\
\hline HFHP & 74 & 696 & 201 & 690 & 92 & 2868 & 1451 & 33110 & 5391 & 3958 & 48531 \\
\hline Stayers Total & 11527 & 62867 & 17469 & 42137 & 25283 & 33897 & 9127 & 60361 & & & 262668 \\
\hline Newcomers & 3607 & 10765 & 4556 & 8715 & 2863 & 6597 & 2852 & 15049 & & & 55004 \\
\hline TOTAL & 15134 & 73632 & 22025 & 50852 & 28146 & 40494 & 11979 & 75410 & 47572 & 63926 & 429170 \\
\hline
\end{tabular}

Note: The sample is restricted to those individuals and firms used in our main analysis (see Table A.4). See Table 1 for the industries classified as "Low/High China" and "Low/High ICT". We divide individuals into four possible groups (LFLP, LFHP, HFLP, HFHP) in Panels A-D, where the two first letters denote the firm type and the two last denote the person type. "LF (HF)" is a firm with fixed effects in bins 1-4 (7-10) of Figure 1 in Period 1. "LP (HP)" is a person with fixed effects in bins 1-4 (7-10) of Figure 1 in Period 1. Individuals in column "Switch" are employed in a manufacturing job in Period 1, but switched to a non-manufacturing job in Period 2. Individuals in column "Exit" leave the sample for whole Period 2, which can be due to an income below the income restriction of 120,000SEK/year, become older than 65, leave to unemployment, leave labor force, retire or die. "Stayers" are individuals present in Periods 1 and 2. "Newcomers" are individuals out of our sample in Period 1 (either because they did not meet the income restriction, were younger than 20 years old, were out of the labor force, unemployed or working outside the manufacturing sector), but who enter the manufacturing sector in Period 2. 
Table A.8: Summary of model parameters

\begin{tabular}{lcc}
\hline & Model & Source \\
\hline Parametrized & & Eurostat \\
Interest rate $(r)$ & 0.035 & Dataset \\
Share of low-skill workers $(p)$ & 0.58 & Albrecht and Vroman (2002) \\
Workers' bargaining power $(\beta)$ & 0.5 & Albrecht and Vroman (2002) \\
Unemployment benefit $(b)$ & 0.1 & Stadin (2015) \\
Job separation rate $(\delta)$ & 0.1 & Albrecht and Vroman $(2002)$ \\
Matching function $(m(\theta))$ & $2 \theta^{0.5}$ & benchmark \\
Higest firm productivity $\left(z^{\max }\right)$ & 1.95 & benchmark 1.2 \\
Returns to skill $(\alpha)$ & $1-1.4$ & \\
\hline & Model & \\
\hline Calibrated & & Source \\
Relative skill $\left(s^{2} / s^{1}\right)$ & 3.3 & Stadin (2015) \\
Relative vacancy cost $\left(c^{2} / c^{1}\right)$ & 4.4 & Dataset \\
\hline
\end{tabular}


Table A.9: Employment effect of a $1 \%$ decrease in the productivity of unqualified jobs $\left(y_{T}^{1}\right)^{\alpha}$ in exposed $(T)$ industry vs. non-exposed $(N)$ industry for the high ICT intensity industries.

\begin{tabular}{|c|c|c|c|c|}
\hline & (1) & (2) & (3) & (4) \\
\hline \multirow[t]{2}{*}{$\mathbf{y}_{\mathrm{T}}^{1}$} & $\frac{\mathrm{e}_{\mathrm{N}}^{\mathrm{s1}}}{\frac{\mathrm{e}_{\mathrm{N}}}{2}}$ & $\frac{\mathbf{e}_{T}^{\mathbf{s 1}}}{\frac{\mathbf{e}_{T}}{T}}$ & $\frac{e_{y 2, N}^{s 2}}{\frac{e_{N}}{e_{n}}}$ & $\frac{e_{y 2, T}^{s 2}}{e_{T}^{s}}$ \\
\hline & \multicolumn{4}{|c|}{ Panel A: Model } \\
\hline 1.500 & 0.453 & 0.453 & 0.484 & 0.484 \\
\hline 1.489 & 0.468 & 0.434 & 0.467 & 0.505 \\
\hline change (\% point) & 1.512 & -1.827 & -1.693 & 2.110 \\
\hline & \multicolumn{4}{|c|}{ Panel B: Data } \\
\hline Period 1 & 0.393 & 0.393 & 0.244 & 0.273 \\
\hline Period 2 & 0.466 & 0.396 & 0.238 & 0.302 \\
\hline change ( $\%$ point) & 6.341 & -0.644 & -1.637 & 2.942 \\
\hline
\end{tabular}

Note: The model employment shares represent the shares of different skills, $s^{1,2}$, on different job types, $y^{1,2}$, in the total industry employment, where the share of $s^{1}$ on $y^{2}$ is 0 by construction. The figures from the data are constructed as follows. $\frac{e_{k}^{s 1}}{e_{k}}, k=N, T$, is the share of low skill workers on the bottom 40 percent of jobs of industry $k$ (i.e. jobs in the low paying firms) in the total industry employemnt. $\frac{e_{y 2, k}^{s 2}}{e_{k}}, k=N, T$, is the share of high skill workers on the top 40 percent of jobs of industry $k$ (jobs in the high paying firms) in the total industry employment.

In the data, we define low (high) skill workers as those workers who in each period have an estimated individual effect in the bottom (top) 40 percent of the distribution of person effects. 
Table A.10: Wage effect of a $1 \%$ decrease in the productivity of unqualified jobs in exposed $(T)$ industry vs. non-exposed $(N)$ industry for the high ICT intensity industries.

\begin{tabular}{|c|c|c|c|c|c|c|c|c|}
\hline & (1) & (2) & (3) & (4) & (5) & (6) & (7) & (8) \\
\hline \multicolumn{9}{|c|}{ Panel A: Model, relative wages by skill and job type } \\
\hline & $\overline{\mathbf{w}}_{\mathbf{y 1}, \mathrm{N}}^{\mathrm{s}}$ & $\overline{\mathbf{w}}_{\mathbf{y 1}, \mathbf{T}}^{\mathbf{s 2}}$ & $\overline{\mathbf{w}}_{\mathbf{y} 1, \mathbf{N}}^{\mathbf{s} 2}$ & $\overline{\mathbf{w}}_{\mathbf{y 1}, \mathbf{T}}^{\mathbf{s}}$ & $\overline{\mathbf{w}_{N}^{s 2}}$ & $\overline{\mathbf{w}}_{T}^{\mathrm{s2}}$ & $\overline{\mathrm{w}}^{\mathrm{s} 2}$ & $\overline{\mathbf{w}}_{T}^{\mathrm{s} 2}$ \\
\hline $\mathbf{y}_{\mathrm{T}}$ & $\overline{\overline{\bar{w}_{N}^{s 1}}}$ & $\overline{\overline{\bar{w}_{T}^{s 1}}}$ & $\overline{\overline{\mathbf{w}_{\mathbf{y} 2, \mathrm{~N}}^{\mathbf{s}}}}$ & $\overline{\overline{\mathbf{w}_{\mathbf{y} 2, T}^{s}}}$ & $\frac{\overline{\bar{w}_{N}^{1}}}{\mathrm{~s}}$ & $\frac{\overline{\overline{\mathrm{w}}_{T}^{\mathrm{sl}}}}{\mathrm{T}}$ & $\overline{\overline{\mathrm{w}}^{\mathrm{S}}}$ & $\overline{\overline{\mathbf{w}_{\mathrm{N}}^{2}}}$ \\
\hline 1.500 & 4.772 & 4.772 & 0.529 & 0.529 & 6.896 & 6.896 & 6.896 & 0.500 \\
\hline 1.489 & 4.803 & 4.805 & 0.528 & 0.529 & 6.947 & 6.948 & 6.947 & 0.500 \\
\hline change $(\%)$ & 0.646 & 0.689 & -0.138 & -0.101 & 0.737 & 0.755 & 0.746 & -0.035 \\
\hline \multirow{3}{*}{$\mathbf{y}_{\mathrm{T}}^{1}$} & \multicolumn{8}{|c|}{ Panel B: Model, relative wage by skill and top $\left(z^{t 40}\right) /$ bottom $\left(z^{b 40}\right) 40 \%$ of $z$} \\
\hline & $\frac{\overline{\mathbf{w}}^{\mathbf{s} 2}\left(\mathbf{z}^{\mathbf{b 4 0}}, \mathbf{N}\right)}{{ }^{\mathbf{s}}}$ & $\frac{\overline{\mathbf{w}}^{\mathbf{s 2}}\left(\mathbf{z}^{\mathbf{b 4 0}}, \mathbf{T}\right)}{-\mathbf{s}}$ & $\frac{\overline{\mathbf{w}}^{\mathbf{s} 2}\left(\mathbf{z}^{\mathbf{b} 40}, \mathbf{N}\right)}{=}$ & $\overline{\mathbf{w}}^{\mathbf{s} \mathbf{2}}\left(\mathbf{z}^{\mathbf{b} 40}, \mathbf{T}\right)$ & $\overline{\bar{w}_{N}^{2}}$ & $\overline{\overline{\mathbf{w}}_{T}^{s 2}}$ & $\overline{\bar{w}^{s 2}}$ & $\underline{\bar{w}_{T}^{\mathbf{s} 2}}$ \\
\hline & $\overline{\overline{\mathbf{w}}_{\mathrm{N}}^{\mathrm{S}}}$ & $\overline{\overline{\mathbf{w}}_{\mathbf{T}}^{s 1}}$ & $\overline{\overline{\mathbf{w}}^{\mathbf{s} 2}\left(\mathbf{z}^{\mathbf{t 4 0}}, \mathbf{N}\right)}$ & $\overline{\overline{\mathbf{w}}^{\mathbf{s} 2}\left(\mathbf{z}^{\mathbf{t 4 0}}, \mathbf{T}\right)}$ & $\frac{\overline{\bar{w}_{N}}}{\mathbf{s}}$ & $\frac{\overline{\overline{\mathrm{w}}_{\mathrm{T}}^{s 1}}}{\mathrm{~s}}$ & $\overline{\overline{\mathrm{w}}}^{\mathbf{1}}$ & $\frac{\overline{w_{N}^{2}}}{\bar{s}^{2}}$ \\
\hline 1.500 & 4.775 & 4.775 & 0.527 & 0.527 & 6.916 & 6.916 & 6.916 & 0.500 \\
\hline 1.489 & 4.806 & 4.755 & 0.527 & 0.526 & 6.966 & 6.894 & 6.930 & 0.500 \\
\hline \multirow[t]{2}{*}{ change $(\%)$} & 0.652 & -0.422 & -0.098 & -0.151 & 0.716 & -0.323 & 0.194 & 0.027 \\
\hline & \multicolumn{8}{|c|}{ Panel B: Data } \\
\hline Period 1 & 1.635 & 1.655 & 0.846 & 0.842 & 1.651 & 1.689 & 1.673 & 1.041 \\
\hline Period 2 & 1.636 & 1.737 & 0.831 & 0.826 & 1.673 & 1.784 & 1.735 & 1.077 \\
\hline change $(\%)$ & 0.017 & 4.927 & -1.765 & -1.992 & 1.300 & 5.606 & 3.676 & 3.497 \\
\hline
\end{tabular}

Note: The model figures represent the relative wages of different skills, $s^{1,2}$, on different job types, $y^{1,2}$ (Panel A), or on jobs in top $\left(z^{t 40}\right)$ and bottom $\left(z^{b 40}\right) 40 \%$ productive firms (panel B), within and across industries. The figures from the data are constructed using wages of workers with different skill on the bottom/top 40 percent of jobs of industry $k$ (i.e. jobs in the low/high paying firms). 
Table A.11: Employment effect of a 1\% decrease in the productivity of unqualified jobs in exposed $(\mathrm{T})$ industry vs. non-exposed $(\mathrm{N})$ industry under different ICT intensity (represented by $\alpha$, return on skill in the production function, varying from 1 to 2.)

\begin{tabular}{|c|c|c|c|c|}
\hline & (1) & $(2)$ & (3) & (4) \\
\hline \multicolumn{5}{|c|}{ Panel A: Unqualified and qualified jobs } \\
\hline$\alpha$ & $\frac{\mathbf{e}_{\mathbf{N}}^{\mathbf{s}}}{\mathbf{e}_{\mathbf{N}}}$ & $\frac{\mathbf{e}_{\mathbf{T}}^{\mathbf{s 1}}}{\mathbf{e}_{\mathbf{T}}}$ & $\frac{\mathrm{e}_{\mathbf{y 2}, \mathrm{N}}^{\mathrm{s} 2}}{\mathbf{e}_{\mathrm{N}}}$ & $\frac{e_{y 2, T}^{s 2}}{e_{T}}$ \\
\hline 1.0 & 1.398 & -1.613 & -1.686 & 2.139 \\
\hline 2.0 & 1.956 & -2.619 & -2.091 & 2.819 \\
\hline \multicolumn{5}{|c|}{ Panel B: Top $\left(z^{t 40}\right)$ and bottom $\left(z^{b 40}\right) 40 \%$ of $z$} \\
\hline$\alpha$ & $\frac{\mathrm{e}^{\mathbf{s} 1}\left(\mathbf{z}^{\mathbf{b 4 0}}, \mathbf{N}\right)}{\mathbf{e}_{\mathbf{N}}}$ & $\frac{\mathbf{e}^{\mathbf{s} 1}\left(\mathbf{z}^{\mathbf{b 4 0}}, \mathbf{T}\right)}{\mathbf{e}_{\mathbf{T}}}$ & $\frac{\mathbf{e}^{\mathbf{s} 2}\left(\mathbf{t}^{\mathbf{t 4 0}}, \mathbf{N}\right)}{\mathbf{e}_{\mathbf{N}}}$ & $\frac{\mathbf{e}^{\mathbf{s} 2}\left(\mathbf{z}^{\mathbf{4 4 0}}, \mathbf{T}\right)}{\mathbf{e}_{\mathbf{T}}}$ \\
\hline 1.0 & 0.888 & -0.944 & -1.319 & 1.659 \\
\hline $\mathbf{2 . 0}$ & 1.956 & -2.619 & -0.259 & 0.334 \\
\hline \multicolumn{5}{|c|}{ Panel C: Top $\left(e^{t 40}\right)$ and bottom $\left(e^{b 40}\right) 40 \%$ of filled jobs } \\
\hline$\alpha$ & $\frac{\mathbf{e}^{\mathbf{s 1}}\left(\mathbf{e}^{\mathbf{b 4 0}}, \mathbf{N}\right)}{\mathbf{e}_{\mathbf{N}}}$ & $\frac{\mathbf{e}^{\mathbf{s} \mathbf{1}\left(\mathbf{e}^{\mathbf{b} 40}, \mathbf{T}\right)}}{\mathbf{e}_{\mathbf{T}}}$ & $\frac{\mathrm{e}^{\mathbf{s} 2}\left(\mathrm{e}^{\mathbf{t 4 0}}, \mathbf{N}\right)}{\mathbf{e}_{N}}$ & $\frac{\mathrm{e}^{\mathbf{s} 2}\left(\mathrm{e}^{\mathbf{t 4 0}}, \mathbf{T}\right)}{\mathbf{e}_{\mathbf{T}}}$ \\
\hline 1.0 & 0.043 & 0.043 & -1.333 & 1.678 \\
\hline $\mathbf{2 . 0}$ & 1.956 & -2.619 & 0.000 & 0.000 \\
\hline \multicolumn{5}{|c|}{ Panel D: Top $60 \%\left(e^{t 60}\right)$ and bottom $40 \%\left(e^{b 40}\right)$ of filled jobs } \\
\hline$\alpha$ & $\frac{\mathrm{e}^{\mathbf{s} \mathbf{1}\left(\mathbf{e}^{\mathbf{b 4 0}}, \mathbf{N}\right)}}{\mathbf{e}_{\mathbf{N}}}$ & $\frac{\mathbf{e}^{\mathbf{s} \mathbf{1}\left(\mathbf{e}^{\mathbf{b 4 0}}, \mathbf{T}\right)}}{\mathbf{e}_{\mathbf{T}}}$ & $\frac{\mathrm{e}^{\mathbf{s} 2}\left(\mathrm{e}^{\mathbf{t 6 0}}, \mathrm{N}\right)}{\mathbf{e}_{\mathrm{N}}}$ & $\frac{\mathrm{e}^{\mathbf{s} 2}\left(\mathrm{e}^{\mathbf{t 6 0}}, \mathbf{T}\right)}{\mathbf{e}_{\mathbf{T}}}$ \\
\hline 1.0 & 0.043 & 0.043 & -1.354 & 1.656 \\
\hline 2.0 & 1.956 & -2.619 & 0.000 & 0.000 \\
\hline
\end{tabular}

Note: The reported figures present the \% point changes in the model employment shares of different skills, $s^{1,2}$, employed at: 1) Panel A: unqualified $\left(y^{1}\right)$ and qualified $\left(y^{2}\right)$ jobs, 2) Panel B: top $\left(z^{t 40}\right)$ and bottom $\left(z^{b 40}\right) 40 \%$ productive firms, 3) Panel C: top $\left(e^{t 40}\right)$ and bottom $\left(e^{b 40}\right) 40 \%$ of filled jobs, and 4) Panel D: top $60 \%\left(e^{t 60}\right)$ and bottom $40 \%\left(e^{b 40}\right)$ of filled jobs, in the total industry employment. 


\section{B Figures}

Figure B.1: Distributions of worker and firm fixed effects by education, 1996-2006.

Panel A: High School Graduates and Dropouts

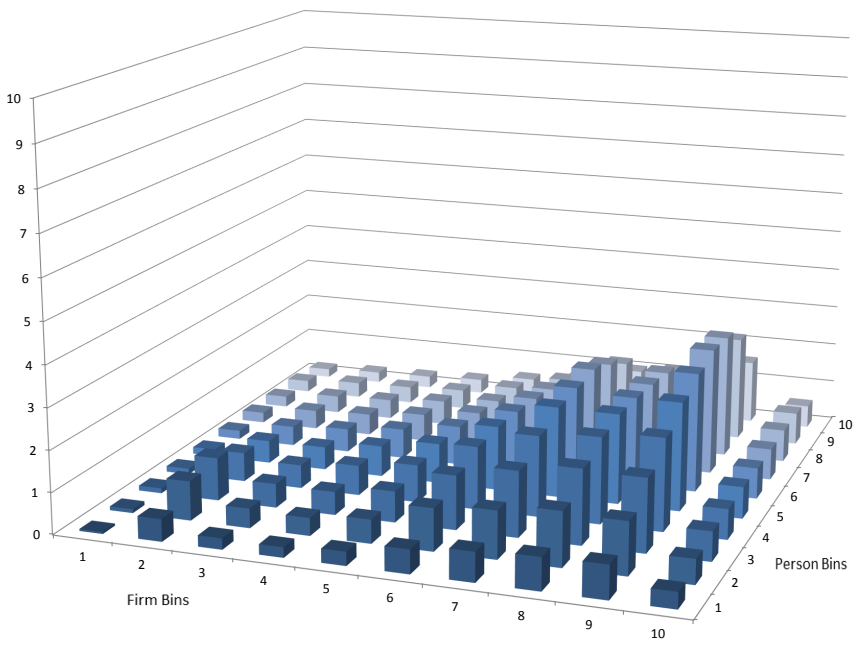

Panel B: College

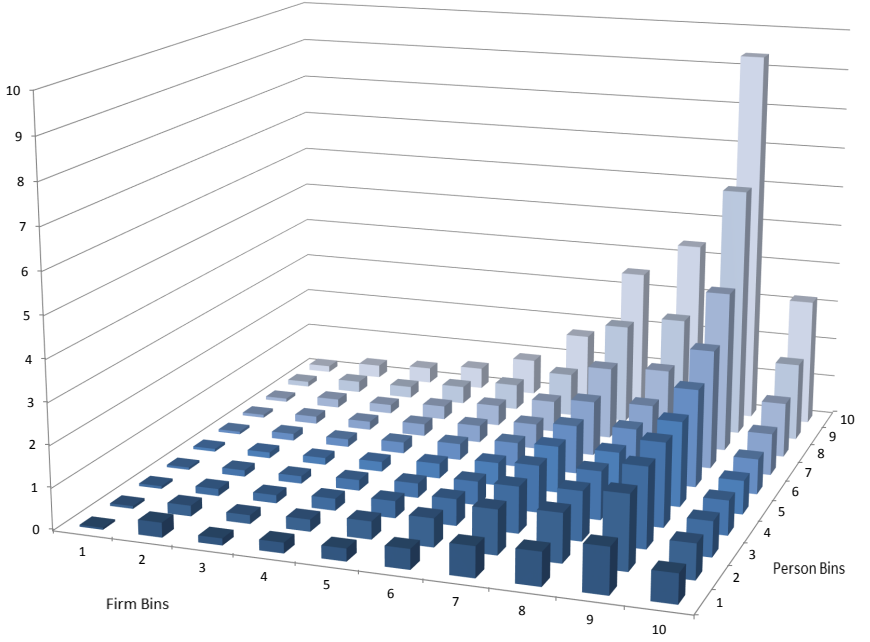

Note: Panels A and B of this figure present the joint distribution of worker and firm fixed effects resulting from estimating model (2) for high school graduates and dropouts (Panel A) and workers with some college (Panel B). The worker and firm fixed effects are ranked by deciles across the distribution of all workers within each group. 


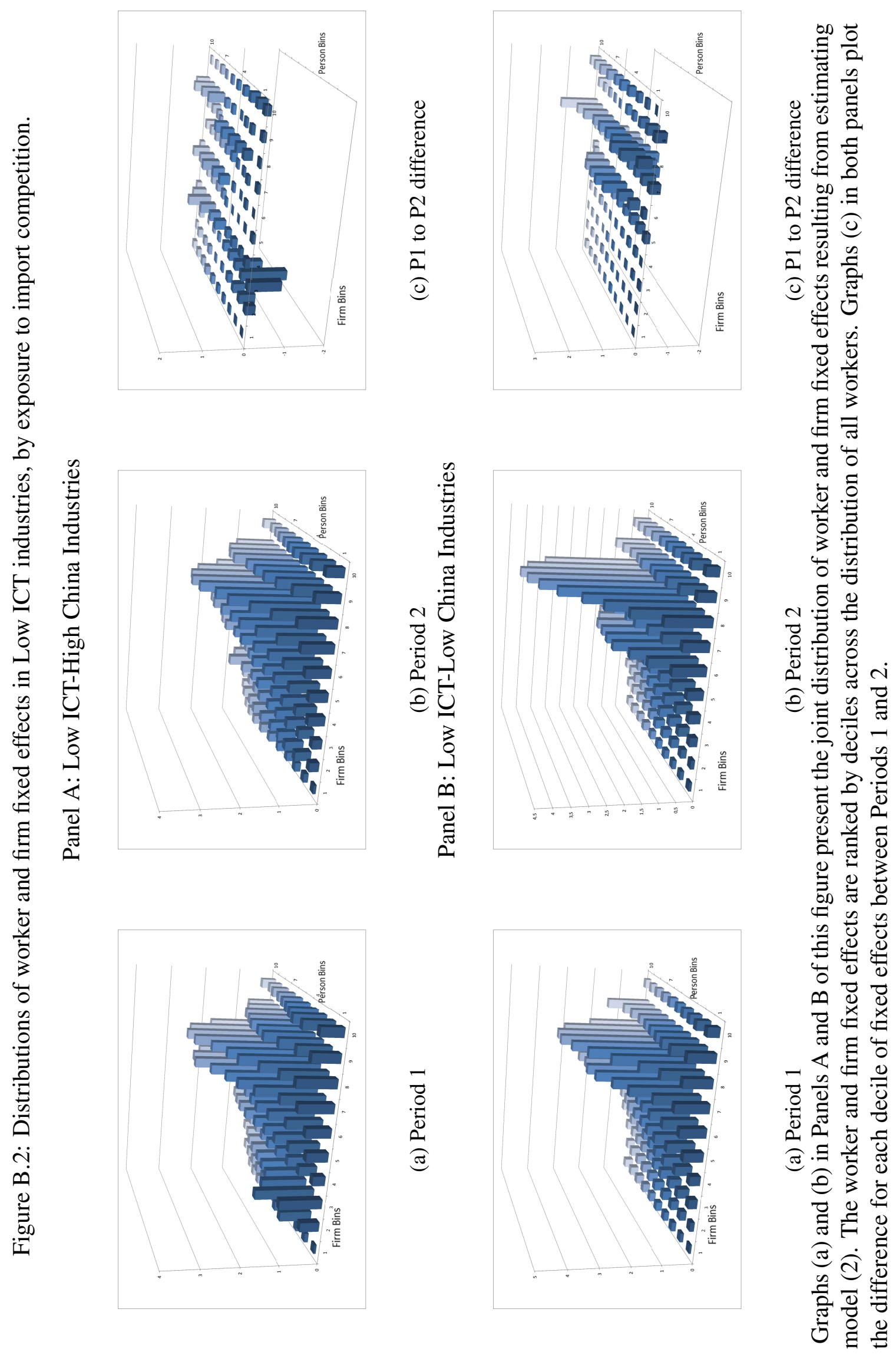




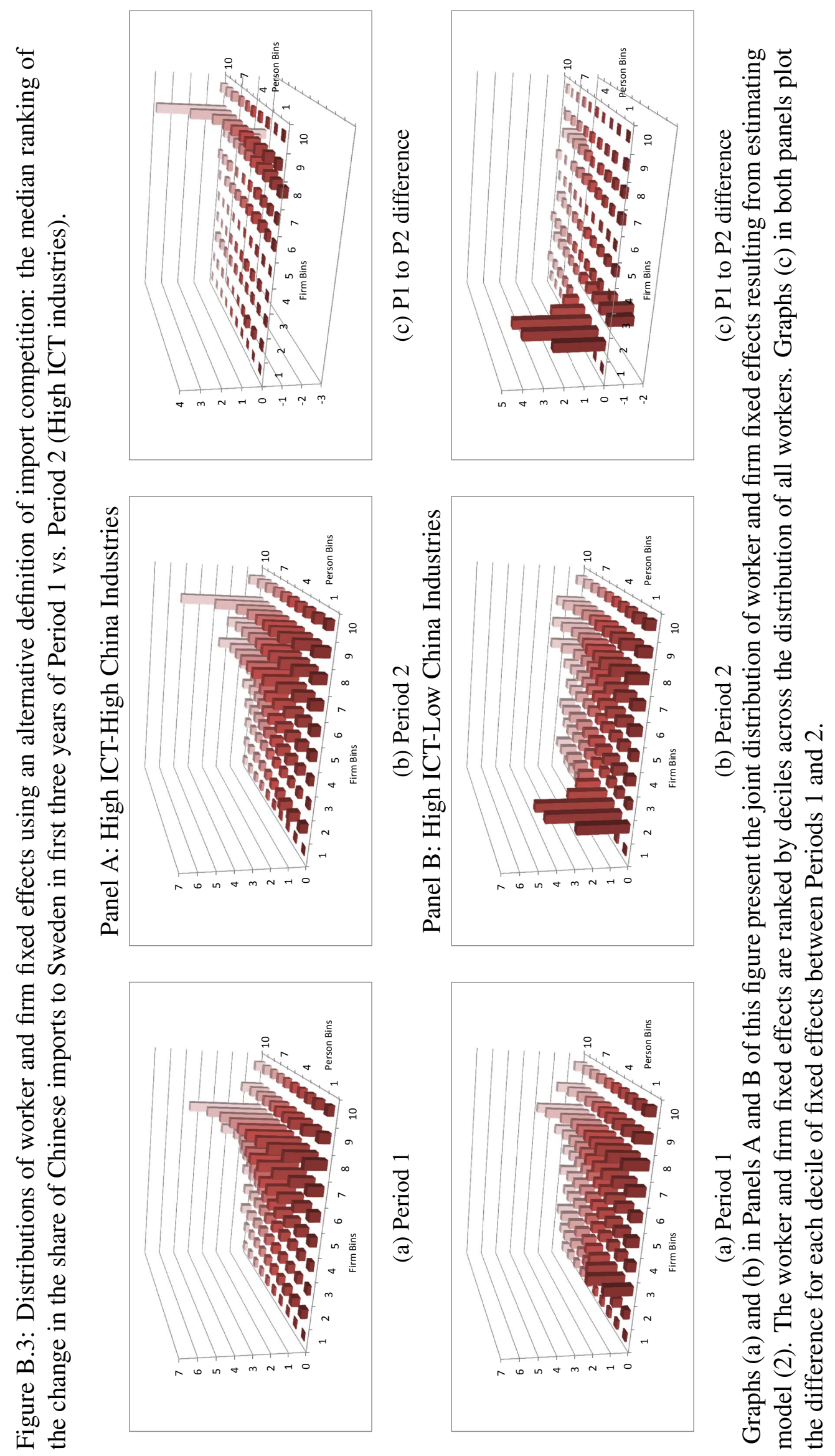




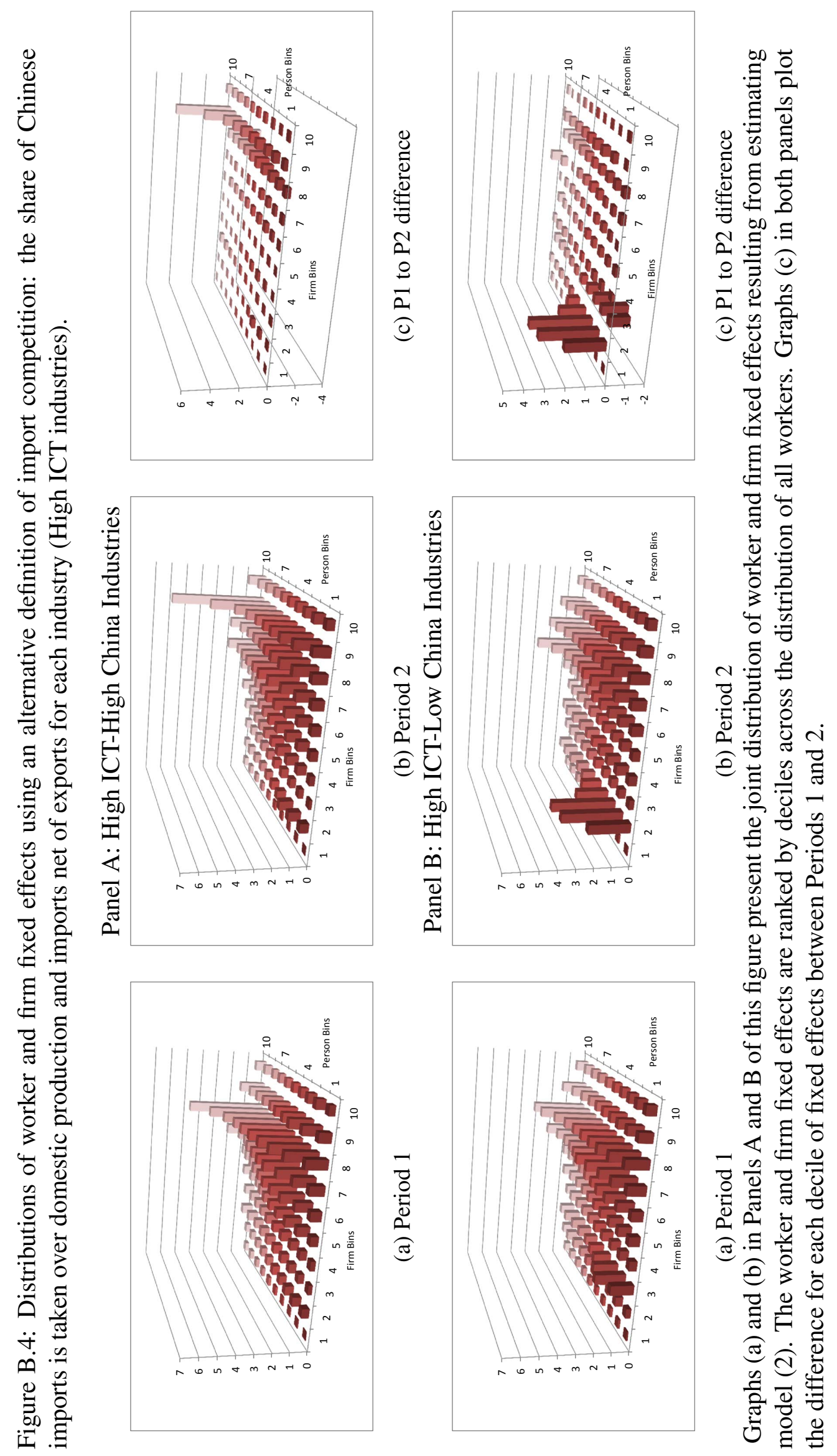


Figure B.5: Average wages at old and destination firms of workers who switch firms within Period 1.

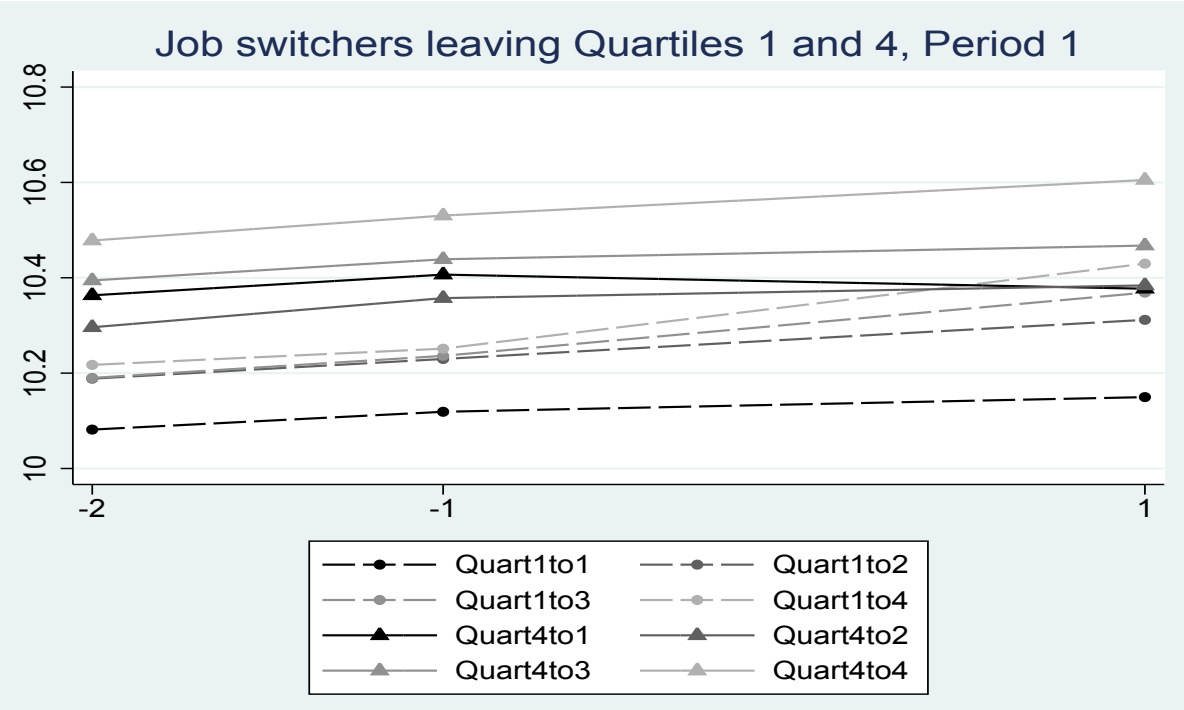

Note: Average wages at old and destination firms of workers who switch from Quartile 1 (dashed) and Quartile 4 (solid) firms to all possible quartiles within Period 1. Firm quartiles are determined by the average wage of the coworkers of the switchers the year before and the year of the switch.

Figure B.6: Average wages at old and destination firms of workers who switch firms within Period 2.

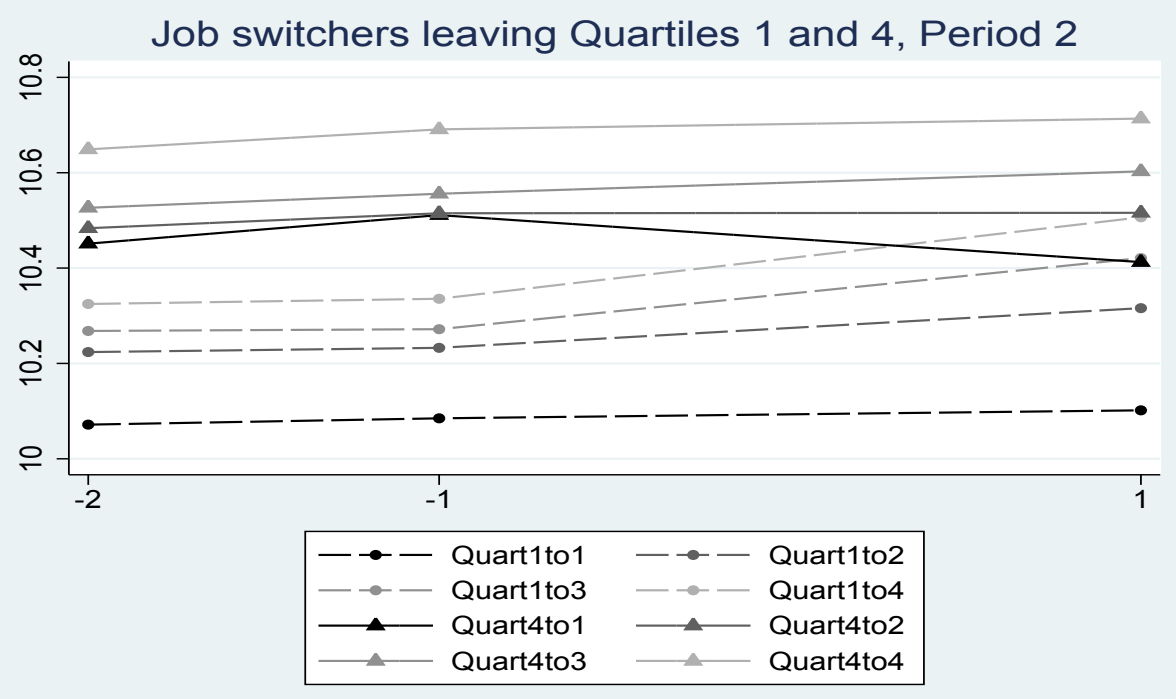

Note: Average wages at old and destination firms of workers who switch from Quartile 1 (dashed) and Quartile 4 (solid) firms to all possible quartiles within Period 2. Firm quartiles are determined by the average wage of the coworkers of the switchers the year before and the year of the switch. 
Figure B.7: Transition probabilities across deciles of the distribution of fixed effects for workers and firms that remain in the sample in Periods 1 and 2.

Panel A: Across worker fixed effects

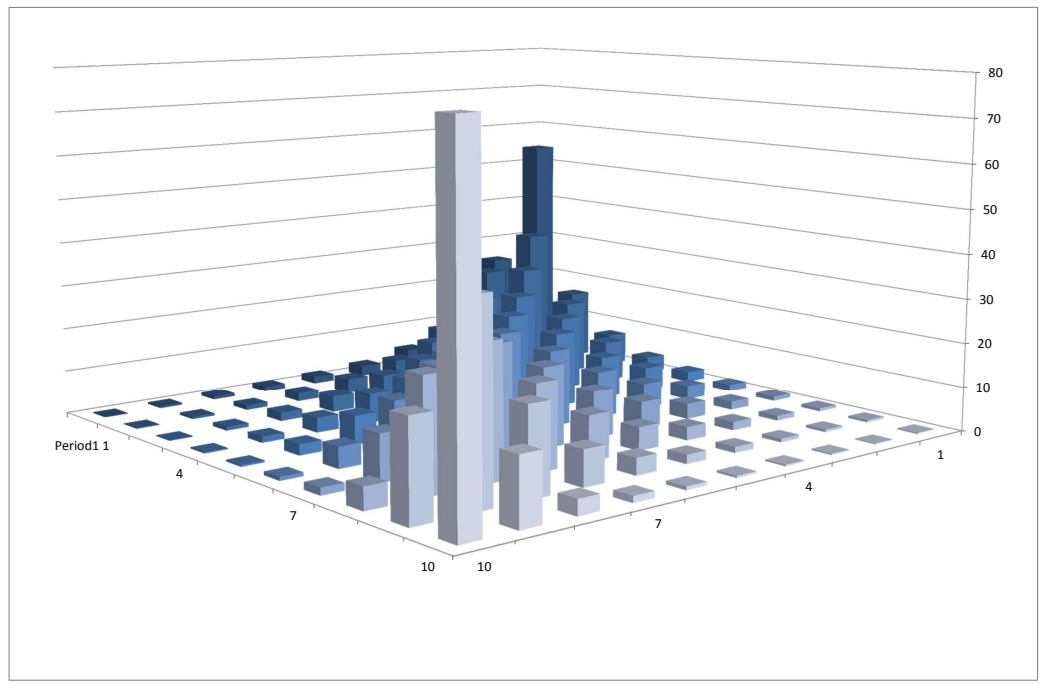

Panel B: Across firm fixed effects

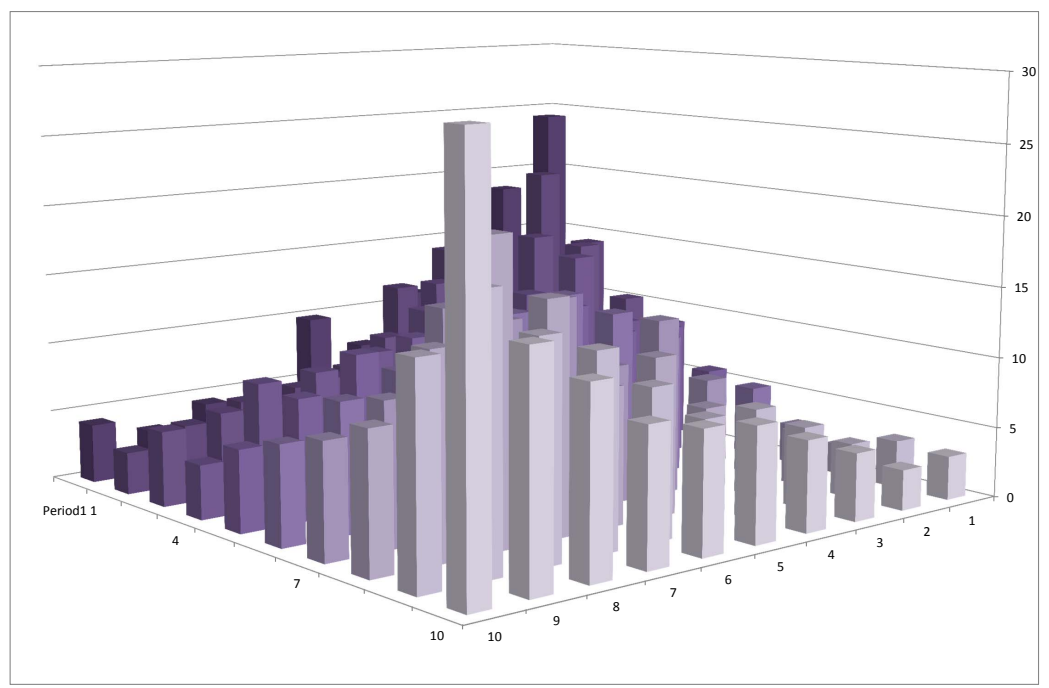


Figure B.8: Productivity cutoffs: the productivity of the marginal exiting firm, $z_{k}^{1}$ in industry $k$, and the productivity of the firm for which the value of opening an unqualified vacancy is equal to the value of opening a qualified vacancy (i.e. it is indifferent between the qualified and unqualified vacancies), $z_{k}^{2}$.

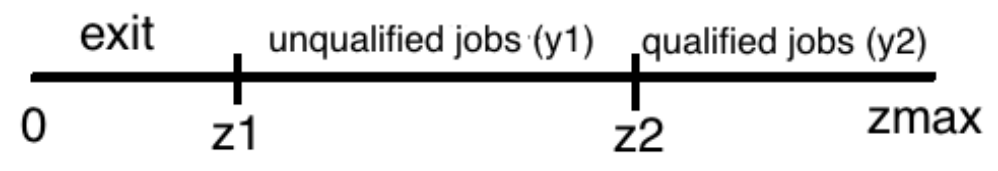

Figure B.9: The effect of increasing ICT intensity represented by a rise in $\alpha$, return on skill in the production function, on the steady-state variables.
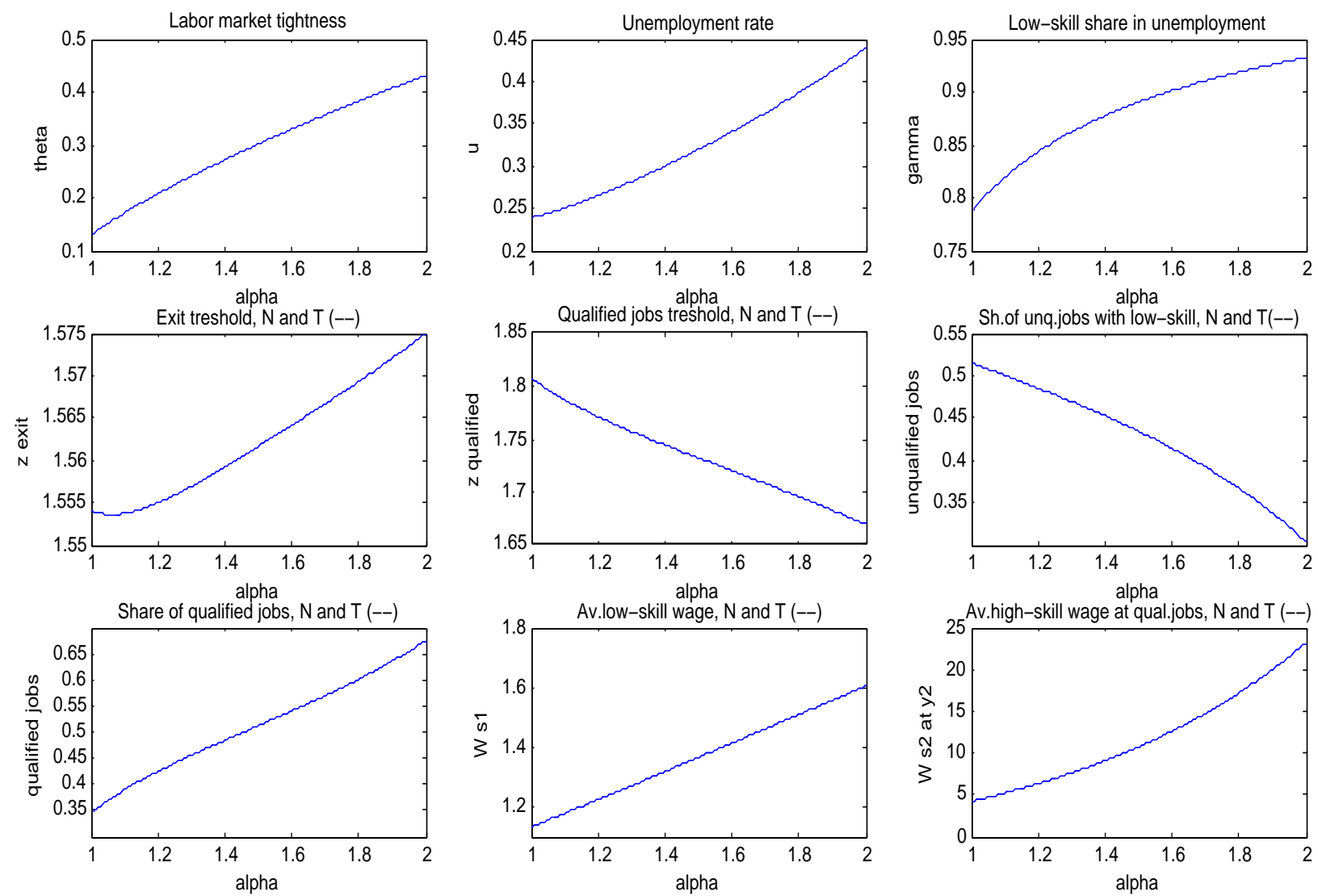


\section{Theoretical Framework}

\section{C.1 The Model}

Matches between vacancies and unemployed workers are formed whenever the total match surplus is non-negative. Denoting the value of unemployment for a worker of type $s$ by $U(s)$, the value of $k$ industry's vacancy of type $y_{k}$ for the firm with productivity $z_{k}$ by $V\left(y_{k}, z_{k}\right)$, the value of employment for a worker of type $s$ at job $y_{k}$ in firm $z_{k}$ by $N\left(s, y_{k}, z_{k}\right)$ and the value of filled job $y_{k}$ with worker $s$ for a firm $z_{k}$ by $J\left(s, y_{k}, z_{k}\right)$. Then, a match is formed if:

$$
N\left(s, y_{k}, z_{k}\right)+J\left(s, y_{k}, z_{k}\right) \geq U(s)+V\left(y_{k}, z_{k}\right) .
$$

Next, we define expressions for the value functions. The value of employment and the value of a filled job are given by

$$
\begin{aligned}
r N\left(s, y_{k}, z_{k}\right) & =w\left(s, y_{k}, z_{k}\right)+\delta\left[U(s)-N\left(s, y_{k}, z_{k}\right)\right] \\
r J\left(s, y_{k}, z_{k}\right) & =f\left(s, y_{k}, z_{k}\right)-w\left(s, y_{k}, z_{k}\right)-c+\delta V\left(y_{k}, z_{k}\right)
\end{aligned}
$$

where $r$ represents the interest rate (common for workers and firms) and $\delta$ is the exogenous match dissolution rate. The values of unemployment for a worker of type $s^{1}$ and $s^{2}\left(U\left(s^{1}\right)\right.$ and $\left.U\left(s^{2}\right)\right)$, respectively, are given by

$$
\begin{aligned}
r U\left(s^{1}\right) & =b+\phi_{N} m(\theta)\left[\bar{N}\left(s^{1}, y_{N}^{1}, z_{N}\right)-U\left(s^{1}\right)\right] \\
& +\phi_{T} m(\theta)\left[\bar{N}\left(s^{1}, y_{T}^{1}, z_{T}\right)-U\left(s^{1}\right)\right] \\
r U\left(s^{2}\right) & =b+m(\theta)\left[\phi_{N} \max \left\{\bar{N}\left(s^{2}, y_{N}^{1}, z_{N}\right)-U\left(s^{2}\right\}, 0\right)\right. \\
& \left.+\left(\frac{v_{N}}{v}-\phi_{N}\right)\left(\bar{N}\left(s^{2}, y_{N}^{2}, z_{N}\right)-U\left(s^{2}\right)\right)\right] \\
& +m(\theta)\left[\phi_{T} \max \left\{\bar{N}\left(s^{2}, y_{T}^{1}, z_{T}\right)-U\left(s^{2}\right\}, 0\right)\right. \\
& \left.+\left(\frac{v_{T}}{v}-\phi_{T}\right)\left(\bar{N}\left(s^{2}, y_{T}^{2}, z_{T}\right)-U\left(s^{2}\right)\right)\right]
\end{aligned}
$$

where $b$ is the fixed unemployment benefit, $\frac{v_{k}}{v}$ represents the share of each $k$-industry's vacancies in the total number of vacancies in the economy and $\phi_{k}$ is the share of industry $k$ 's unqualified vacancies in the total number of vacancies in the economy. The max operator in the value of unemployment for the high skill worker denotes this worker's choice of forming the match depending on the expected surplus when matched with an unqualified vacancy. $\bar{N}\left(s^{j}, y_{k}^{j}, z_{k}\right)$ stands for the expected value of employment for the worker of skill $j=1,2$ and it is a function of the expected (average) productivity of the firm that the worker may be matched to.

Finally, the value of vacancy is given by

$$
\begin{aligned}
r V\left(y_{k}^{1}, z_{k}\right) & =-c^{1}+\frac{m(\theta)}{\theta}\left[\gamma\left(J\left(s^{1}, y_{k}^{1}, z_{k}\right)-V\left(y_{k}^{1}, z_{k}\right)\right)\right. \\
& \left.+(1-\gamma) \max \left\{J\left(s^{2}, y_{k}^{1}, z_{k}\right)-V\left(y_{k}^{1}, z_{k}\right), 0\right\}\right] \\
r V\left(y_{k}^{2}, z_{k}\right) & =-c^{2}+\frac{m(\theta)}{\theta}(1-\gamma)\left[J\left(s^{2}, y^{2}, z\right)-V\left(y^{2}, z\right)\right] .
\end{aligned}
$$


Again, the max operator in the value of the unqualified vacancy denotes the choice of the firm with this type of vacancy to form the match with a high skill worker depending on the size of the respective surplus. We will focus on the equilibria in which the parameters of the model are such that the matches between unqualified vacancies and high skill workers are profitable.

Substituting the value functions into (12), the match is formed if and only if

$$
f\left(s, y_{k}, z_{k}\right)-c_{k} \geq r\left(U(s)+V\left(y_{k}, z_{k}\right)\right) .
$$

The wages for each industry, job type, firm and worker type are determined by Nash bargaining condition

$$
N\left(s, y_{k}, z_{k}\right)-U(s)=\beta\left[N\left(s, y_{k}, z_{k}\right)+J\left(s, y_{k}, z_{k}\right)-U(s)-V\left(y_{k}, z_{k}\right)\right],
$$

with $\beta$ as the worker's share of surplus, which yields the wage expression

$$
w\left(s, y_{k}, z_{k}\right)=\beta\left(f\left(s, y_{k}, z_{k}\right)-c-r V\left(y_{k}, z_{k}\right)\right)+(1-\beta) r U(s) .
$$

Substituting the vacancy flows conditions (8) and (9), and the total number of vacancies in the economy $v_{N}^{1}+v_{T}^{1}+v_{N}^{2}+v_{T}^{2}=v=\theta u$ into the expressions for each industry's share of unqualified vacancies in the economy, the following is obtained

$$
\begin{aligned}
& \phi_{N}=\frac{v_{N}^{1}}{\theta u}=\frac{\delta\left(z_{N}^{2}-z_{N}^{1}\right)}{\frac{m(\theta)}{\theta}+\delta} \frac{1}{\theta u} \\
& \phi_{T}=\frac{v_{T}^{1}}{\theta u}=\frac{\delta\left(z_{T}^{2}-z_{T}^{1}\right)}{\frac{m(\theta)}{\theta}+\delta} \frac{1}{\theta u} .
\end{aligned}
$$

The shares of each industry's qualified vacancies in the total number of vacancies in the economy are defined similarly.

\section{C.2 Calibration}

The interest rate $(r)$ is set to 0.035 based on the Swedish average interest rate data provided by the Eurostat (short to long run rates averages range from 3.29 to 4.72 in the 1996-2006 period). We refer to our data set and set the share of workers with low skill in the labour force $(p)$ at 0.58 . We classify workers as low- or high-skill based on their individual wage component. We consider low-skill the workers who are in the bottom $60 \%$ of individual fixed effects. Note that this measure does not include unemployed individuals. As the share of low-skill labour in the pool of unemployed may be higher, our value of the low-skill share in the total labour force is possibly biased downwards. However, the share of low-skill workers out of those who leave employment after Period 1 is similar to this ratio, and thus use the value above.

Following Albrecht and Vroman (2002), we set $\beta=0.5$ (workers bargaining power) and $b=$ 0.1 (unemployment benefits). Following Stadin (2015), we set $\delta=0.1$ (job separation rate) and assume a matching function of the form $m(\theta)=2 * \theta^{0.5}$. The highest value of firm productivity in both industries $\left(z^{\max }\right)$ is set to 1.95 . Finally, the parameter $\alpha$, measuring the returns to skill in the production function, varies from 1 to 1.4 to represent the difference in ICT intensity across industries, where high $\alpha(1.4)$ represent the group of ICT intensive industries and the value of 1.2 
is used for the benchmark calibration.

We calibrate the relative skill $s^{2} / s^{1}$ and the relative vacancy cost $c^{2} / c^{1}$ to match the labour market tightness and the unemployment rate in the Swedish data. Stadin (2015) reports the aggregate labour market tightness in Sweden in 1992-2011 to be 0.1. The aggregate unemployment rate in 1996-2006 varied between 6\% and 11\% 29 . The unemployment sector in our model represents the outside option, i.e. it bundles the measures of unemployment, workers leaving manufacturing or leaving the labour force. Therefore, the model equilibrium unemployment rates are higher compared to their data counterparts. In the data we find that the ratio of workers who leave the manufacturing jobs between Period 1 and Period 2 (switch to services, unemployment or leave the labour force) relative to total employment in Period 1 is 0.3 ; and the ratio of workers who leave the manufacturing jobs between Period 1 and Period 2 (switch to services, unemployment or leave the labour force) relative to total employment in both periods (which includes the newly employed in Period 2) is 0.26. Based on this evidence and the model limitations, we allow for a higher unemployment rate in our calibration (0.2-0.3, depending on the industry type) than the one reported by Statistics Sweden.

The calibration yields $s^{2} / s^{1}=3.3$ and $c^{2} / c^{1}=4.4$. Given the lack of linear vacancy cost estimates for Sweden, we follow Stadin (2015) where the vacancy cost is $32 \%$ of the equilibrium wage. A 0.4 cost for the unqualified vacancy is consistent with this measure, which yields the qualified vacancy cost of 3.5. Finally, we set the two skill levels at 1.5 and 5 for $s^{1}$ and $s^{2}$, respectively.

\section{C.3 Numerical Results}

In the data, we track the changes in the share of low and high skill workers in the low and high paying firms as described in the main text. In the model, workers are distinguished by the skill levels, i.e. $s^{1}$ and $s^{2}$, while the firm type is a function of the productivity $z$ and the choice of the job type, $y^{1}$ or $y^{2}$. Besides the job type, we take into account two alternative model counterparts of low and high firm types: 1) the top and bottom $40 \%$ of the productivity $z$ distribution firms, and 2) firms that are either in the top $60 \%$ or bottom $40 \%$ of the firm-wage distribution of the total industry. Table (C.1) reports the results for the two alternative measures.

In both the model and the data, there is an increase in the share of high-skill employment in the high paying firms in the exposed industry $(T)$, absolute and relative to low-skill employment in the low paying firms. In the non-exposed industry $(N)$, we observe an absolute and a relative increase in the share of low-skill employment in the low paying firms. Under the second alternative measure of low and high firm types we use an asymmetric measure (top 60\% and bottom $40 \%$ paying jobs) since the symmetric measure (top and bottom paying $40 \%$ of industry jobs) does not capture some of the effects. With the benchmark parameters, the top paying $40 \%$ of jobs are always filled only with high skill workers, i.e. there is no change in their share with the increase in Chinese import penetration.

\footnotetext{
${ }^{29}$ See http://www.statistikdatabasen.scb.se/pxweb/en/ssd/.
} 
Table C.1: Alternative employment shares: Employment effect of a 1\% decrease in the productivity of unqualified jobs $\left(y_{T}^{1}\right)^{\alpha}$ in exposed $(T)$ industry vs. non-exposed $(N)$ industry for the high ICT intensity industries.

\begin{tabular}{|c|c|c|c|c|}
\hline & (1) & (2) & (3) & (4) \\
\hline \multicolumn{5}{|c|}{ Panel A: Top $\left(z^{t 40}\right)$ and bottom $\left(z^{b 40}\right) 40 \%$ of $z$} \\
\hline $\mathrm{v}^{1}$ & $\underline{\mathrm{e}^{\mathbf{s 1}}\left(\mathbf{z}^{\mathbf{b} 40}, \mathbf{N}\right)}$ & ${\underline{\mathrm{e}^{\mathbf{s 1}}\left(\mathbf{z}^{\mathbf{b 4 0}}, T\right)}}^{T}$ & $\mathrm{e}^{\mathbf{s 2}\left(\mathbf{z}^{\mathbf{t 4 0}}, \mathrm{N}\right)}$ & $\underline{\mathbf{e}^{\mathbf{s 2}}\left(\mathbf{z}^{\mathbf{t 4 0}}, \mathbf{T}\right)}$ \\
\hline $\mathbf{y}_{\mathrm{T}}$ & $\overline{\mathbf{e}_{\mathbf{N}}}$ & $\overline{\mathbf{e}_{\mathbf{T}}}$ & $\overline{\mathbf{e}_{\mathbf{N}}}$ & $\mathbf{e}_{\mathbf{T}}$ \\
\hline 1.500 & 0.382 & 0.382 & 0.368 & 0.368 \\
\hline 1.489 & 0.391 & 0.371 & 0.367 & 0.369 \\
\hline change (\% point) & 0.947 & -1.120 & -0.113 & 0.122 \\
\hline \multicolumn{5}{|c|}{ Panel B: Top $\left(e^{t 40}\right)$ and bottom $\left(e^{b 40}\right) 40 \%$ of filled jobs } \\
\hline $\mathrm{y}^{1}$ & $\underline{\mathrm{e}^{\mathbf{s 1}}\left(\mathrm{e}^{\mathrm{b} 40}, \mathrm{~N}\right)}$ & ${\underline{\mathrm{e}^{\mathbf{s} 1}\left(\mathrm{e}^{\mathbf{b 4 0}}, \mathrm{T}\right)}}^{.}$ & ${\underline{\mathrm{e}^{\mathrm{s} 2}\left(\mathrm{e}^{\mathrm{t} 40}, \mathrm{~N}\right)}}$ & $\underline{\mathrm{e}^{\mathbf{s 2}}\left(\mathrm{e}^{\mathrm{t} 40}, \mathrm{~T}\right)}$ \\
\hline $\mathbf{y}_{\mathrm{T}}$ & $\overline{\mathbf{e}_{\mathbf{N}}}$ & $\overline{\mathbf{e}_{\mathbf{T}}}$ & $\overline{\mathbf{e}_{\mathbf{N}}}$ & $\mathbf{e}_{\mathbf{T}}$ \\
\hline 1.500 & 0.351 & 0.351 & 0.000 & 0.000 \\
\hline 1.489 & 0.351 & 0.351 & 0.000 & 0.000 \\
\hline change (\% point) & 0.020 & 0.020 & 0.000 & 0.000 \\
\hline \multicolumn{5}{|c|}{ Panel C: Top $60 \%\left(e^{t 60}\right)$ and bottom $40 \%\left(e^{b 40}\right)$ of filled jobs } \\
\hline $\mathbf{v}_{T}^{1}$ & $\mathrm{e}^{\mathrm{s1}}\left(\mathrm{e}^{\mathrm{b} 40}, \mathrm{~N}\right)$ & $\mathbf{e}^{\mathbf{s 1}}\left(\mathbf{e}^{\mathbf{b} 40}, \mathbf{T}\right)$ & $\mathrm{e}^{\mathrm{s2}}\left(\mathrm{e}^{\mathrm{t} 60}, \mathrm{~N}\right)$ & $\mathrm{e}^{\mathrm{s} 2}\left(\mathrm{e}^{\mathrm{t} 60}, \mathrm{~T}\right)$ \\
\hline $\mathbf{y}_{\mathbf{T}}$ & $\mathbf{e}_{\mathbf{N}}$ & $\overline{\mathbf{e}_{\mathbf{T}}}$ & $\overline{\mathbf{e}_{\mathbf{N}}}$ & $\mathbf{e}_{\mathbf{T}}$ \\
\hline 1.500 & 0.351 & 0.351 & 0.498 & 0.498 \\
\hline 1.489 & 0.351 & 0.351 & 0.483 & 0.517 \\
\hline change (\% point) & 0.020 & 0.020 & -1.492 & 1.847 \\
\hline
\end{tabular}

Note: The model employment shares represent the shares of different skills, $s^{1,2}$, employed at: 1) Panel A: top $\left(z^{t 40}\right)$ and bottom $\left(z^{b 40}\right) 40 \%$ productive firms, 2) Panel B: top $\left(e^{t 40}\right)$ and bottom $\left(e^{b 40}\right) 40 \%$ of filled jobs, and 3) Panel C: top $60 \%\left(e^{t 60}\right)$ and bottom $40 \%\left(e^{b 40}\right)$ of filled jobs, in the total industry employment. 


\section{C.4 Varying ICT intensity}

In the final exercise, we analyse the effects of an increase in Chinese import penetration in low ICT industries. We use a lower value of $\alpha$ to represent a lower degree of ICT intensity. Given the production technology $f\left(s, y^{1}, z\right)=\left(y^{1}\right)^{\alpha} z=\left(s^{1}\right)^{\alpha} z$ for unqualified and $f\left(s, y^{2}, z\right)=\left(y^{2}\right)^{\alpha} z=$ $\left(s^{2}\right)^{\alpha} z$ for qualified jobs, a lower $\alpha>1$ implies a lower productivity of both job types for any given $z$ iff $s^{1}, s^{2}>1$. For a given $z$, a reduction in $\alpha$ is also implying a reduction in relative productivity of the qualified job with respect to the unqualified job, $\left(s^{2} / s^{1}\right)^{\alpha}$, for any $s^{2}>s^{1}$. Thus, a lower $\alpha$ industries exhibit also a lower relative return of high- to low-skill compared to high $\alpha$ (high ICT intensity) industries. In high ICT intensity industries, a high skill worker is complementing an ICT intensive technology and produces a relatively higher return.

To represent an increase in Chinese import penetration, we again reduce the productivity of unqualified jobs in industry $T\left(y^{1}\right)$, leaving the jobs productivity in industry $N$ unchanged. With $\alpha, y^{1}>1$, the first derivative of the production function with respect to job productivity is positive and, for $y^{1}$ not too small, this derivative is lower for a lower $\alpha^{30}$. Moreover, the derivative is increasing slower with $y^{1}$ for lower $\alpha$ (second derivative is positive and increasing in $\left.\alpha\right)^{31}$. This ensures that the output is less reactive to the job productivity changes in low ICT intensity industries, making the two choices firms are facing (exit and job type choice) less sensitive to the variation in unqualified job productivity. A lower $\alpha$ implies lower labour market tightness, unemployment rate and the share of low-skill workers in unemployment. The range of firms with qualified jobs decreases (exit threshold productivity falls while the job type threshold rises). The share of qualified jobs in total industry employment falls and the share of unqualified jobs with low-skill labour rises. The average wages of low-skill labour on unqualified jobs and the skilled labour on qualified jobs fall. We believe these features capture the difference between the industries with low and high ICT intensity technology, respectively, and their complementarity to skill.

While the effects of a $1 \%$ decrease in $\left(y_{T}^{1}\right)^{\alpha}$ within the low ICT intensity industries group are of the same nature and sign as in the high ICT intensity industries group, the magnitude of the changes is lower. Not all the effects are monotone for the very high or very low $\alpha$, but in general, the employment shares changes become weaker with a decline in $\alpha$. The results point to the interactions of the ICT technology and Chinese import penetration, as defined in our theoretical exercise.

$$
\begin{aligned}
& 30 \quad \frac{d\left(y^{1}\right)^{\alpha}}{d y^{1}}=\alpha\left(y^{1}\right)^{(\alpha-1)}>0 \\
& \frac{d\left[\alpha\left(y^{1}\right)^{(\alpha-1)}\right]}{d \alpha}=\left(y^{1}\right)^{\alpha-1}\left[1+\alpha \ln \left(y^{1}\right)\right]>0 \text { for } y^{1}>e^{-1 / \alpha} \\
& 31 \quad \frac{d^{2}\left(y^{1}\right)^{\alpha}}{d y^{1}}=\alpha(\alpha-1)\left(y^{1}\right)^{(\alpha-2)}>0 \text { for } \alpha>1 \\
& \frac{d\left[\alpha(\alpha-1)\left(y^{1}\right)^{(\alpha-2)}\right]}{d \alpha}=\left(y^{1}\right)^{\alpha-2}\left[(2 \alpha-1)+\left(\alpha^{2}-\alpha\right) \ln \left(y^{1}\right)\right]>0 \text { for } y^{1}>e^{\frac{-2 \alpha+1}{\alpha^{2}-\alpha}}
\end{aligned}
$$

